\title{
A novel zebrafish model of SPEG-related centronuclear myopathy (CNM): characterization and comparison with other CNM model zebrafish
}

Karla G. Espinosa ${ }^{1,2^{*}}$, Salma Geissah ${ }^{1,2^{*}}$, Linda Groom ${ }^{3}$, Jonathan Volaptti ${ }^{1}$, Ian C. Scott ${ }^{4}$, Robert T. Dirksen $^{3}$, Mo Zhao, \#, and James J. Dowling ${ }^{1,2,4, \#}$

1. Program for Genetics and Genome Biology, Hospital for Sick Children, 686 Bay Street, Toronto, Ontario, M5G 0A4, Canada.

2. Department of Molecular Genetics, University of Toronto, Medical Science Building, Room 4386, 1 King's College Cir, Toronto, Ontario, M5S 1A8, Canada.

3. Department of Pharmacology and Physiology, University of Rochester Medical Centre, 601 Elmwood Avenue, Rochester, New York, 14642, USA.

4. Program for Development \& Stem Cell Biology, Hospital for Sick Children, 686 Bay Street, Toronto, Ontario, M5G 0A4, Canada

5. Department of Pediatrics, University of Toronto, Room 1436D, 555 University Avenue, Toronto, Ontario, M5G 1X8, Canada.

*both authors contributed equally

${ }^{\#}$ Co-corresponding authors

Mo Zhao and James J. Dowling

686 Bay Street

Toronto, ON M5G 0A4,

Canada

mo.zhao@sickkids.ca; james.dowling@sickkids.ca 


\title{
Summary Statement
}

We created a novel zebrafish speg mutant model of centronuclear myopathy that recapitulates key features of the human disorder and provides insight into pathomechanisms of the disease.

\begin{abstract}
Centronuclear myopathy (CNM) is a congenital neuromuscular disorder caused by pathogenic variation in genes associated with membrane trafficking and excitation-contraction coupling (ECC). Bi-allelic autosomal recessive mutations in striated muscle enriched protein kinase (SPEG) account for a subset of CNM patients. Previous research has been limited by the perinatal lethality of Speg knockout mice. Thus, the precise biological role of SPEG in skeletal muscle remains unknown. To address this issue, we generated zebrafish spega, spegb, and spega/spegb (speg-DKO) mutant lines. We demonstrate that speg-DKO zebrafish faithfully recapitulate multiple phenotypes associated with human CNM, including disruption of the ECC protein machinery, dysregulation of calcium homeostasis during ECC, and impairment of muscle performance. Taking advantage of the availability of zebrafish models of multiple CNM genetic subtypes, we compared novel and known disease markers in speg-DKO with $m t m 1-K O$ and DNM2-S619L transgenic zebrafish. We observed desmin (DES) accumulation common to all CNM subtypes, and DNM2 upregulation in muscle of both speg-DKO and mtml-KO zebrafish. In all, we establish a new model of SPEG-related CNM, and identify abnormalities in this model suitable for defining disease pathomechanisms and evaluating potential therapies.
\end{abstract}

\section{Keywords}

centronuclear myopathy, disease model, excitation-contraction coupling, muscle, SPEG, zebrafish 


\section{Introduction}

Congenital myopathies are neuromuscular disorders that typically present at birth with hypotonia and weakness (Louis et al., 2022). The prevalence of congenital myopathies is at least 1 in 26,000 (Amburgey et al., 2011). A common congenital myopathy subtype is centronuclear myopathy (CNM), which is defined pathologically by perinuclear organelle disorganization and increased centralized myofibre nuclei, and is clinically associated with respiratory failure, wheelchair dependence, and early mortality (Nance et al., 2012, Jungbluth et al., 2008). CNM is a genetic disease, caused by pathogenic variants in at least five genes: X-linked recessive CNM (XLMTM) caused by MTM1 (myotubularin 1) (Laporte et al., 1996), autosomal dominant CNM caused by DNM2 (dynamin 2) (Bitoun et al., 2005), and autosomal recessive forms of CNM caused by BIN1 (bridging integrator 1) (Nicot et al., 2007a), RYR1 (ryanodine receptor 1) (Wilmshurst et al., 2010), and SPEG (striated muscle enriched protein kinase) (Agrawal et al., 2014b).

Most mutations reported in CNM patients are associated with primary or secondary defects of the excitation-contraction coupling (ECC) machinery (Gonorazky et al., 2018, Tasfaout et al., 2018, Jungbluth et al., 2008, Dowling et al., 2021). In skeletal muscle, ECC occurs at triads, which consist of centrally located sarcolemmal invaginations called transverse tubules (or T-tubules) flanked on either side by terminal cisternae of the sarcoplasmic membranes (or tSRs) (Fig. 1A). These junctional membranes are connected by a mechanical interaction between the CaV1.1 subunit of the dihydropyridine receptor (DHPR) in the T-tubule membrane (with additional essential proteins including STAC3 and the DHPR $\beta 1 \mathrm{a}$ subunit) and the ryanodine receptor 1 (RyR1) $\mathrm{Ca}^{2+}$ release channels in the tSR. ECC is initiated when an action potential propagates down the T-tubule to cause voltage-driven conformational changes in DHPR, which then trigger activation of RyR1 to release $\mathrm{Ca}^{2+}$ stored in the tSR. The resulting surge in myoplasmic $\mathrm{Ca}^{2+}$ promotes actin-myosin cross bridging and sarcomere shortening (i.e. muscle contraction). Notably, although the DHPR/RyR1 interaction is essential for ECC function, the junctional membranes of the triad develop independently to the recruitment of DHPR or RyR1 to the region [as reviewed by (A1-Qusairi and Laporte, 2011)]. The tSR membrane also contains structural/regulatory proteins such as triadin, junctin, and calsequestrin (Zhang et al., 1997, Park et al., 2004), as well as other regulatory proteins that modulate RyR1 channel activity and maintain RyR1 integrity (Zhang et al., 1997, Costello et al., 1986, Treves et al., 2009, Ríos and Györke, 2009, Guo and Campbell, 1995, Wium et al., 2016, Caswell et al., 1999, Groh et al., 1999, Goonasekera et al., 2007). While many of the molecular 
components of the triad are known, the precise molecular mechanisms that underlie triad formation and maintenance, as well as triad disruptions in CNM, remain largely elusive.

SPEG encodes a serine/threonine-specific protein kinase that belongs to the Obscurin/MLCK family (Fleming et al., 2021). SPEG contains two serine/threonine kinase domains, two Fibronectin-Type III (Fn) domains, and nine Immunoglobulin (Ig) domains (Fig. 1B). SPEG is predominantly expressed in striated muscles, but also found in the brain (Quick et al., 2017). Previous research suggests that SPEG interacts with proteins involved in the ECC pathway (Agrawal et al., 2014b, Quick et al., 2017, Quan et al., 2019, Huntoon et al., 2018). SPEG is co-localized with RyR1 (Agrawal et al., 2014b), and interacts with MTM1 (Agrawal et al., 2014b) and DES (desmin) (Luo et al., 2020) (Fig. 1B). Bi-allelic variants in SPEG have been identified to cause CNM in a small number of families (Agrawal et al., 2014b, Wang et al., 2017, Wang et al., 2018, Lornage et al., 2018, Qualls et al., 2019, Tang et al., 2019, Conlon et al., 2020, Almannai et al., 2021, Zhang et al., 2021) (Fig. 1B). Mutations span different regions of the SPEG gene and most are nonsense, resulting in decreased levels of the SPEG protein. Patients with SPEG mutations have skeletal muscle weakness as well as dilated cardiomyopathy (DCM). In severe cases, neonatal mortality has been reported (Agrawal et al., 2014b, Liu et al., 2009, Wang et al., 2018, Qualls et al., 2019, Tang et al., 2019). At present, it is unclear how SPEG regulates muscle development, particularly triad formation and/or function, and why mutations in SPEG lead to $\mathrm{CNM}$.

SPEG shares high sequence conservation across vertebrates. In humans, a single SPEG locus produces a $\sim 10.8 \mathrm{~kb}$ transcript that encodes a 3267 amino acid (a.a.) protein (NP_005867.3). In mice, the Speg locus includes two alternative transcription start sites that produce four distinct isoforms: Apeg (aortic preferentially expressed gene), Bpeg (brain preferentially expressed gene), and Speg $\alpha$, and Speg $\beta$ (Hsieh et al., 2000). Of these, the two longest (Speg $\beta, 3262$ a.a., NP_031489.4; and Spega, 2527 a.a., NP_001078839.1) are the striated muscle isoforms, and are well conserved with human SPEG. The striated muscle isoforms are involved in the maturation and differentiation of neonatal cardiomyocytes, while Spega is the predominant isoform involved in skeletal muscle differentiation (Liu et al., 2009, Hsieh et al., 2000). The zebrafish, however, possess two separate speg genes, spega (Chromosome 6, NP_001007110.1) and spegb (Chromosome 9, XP_021334681), each encoding a single Speg transcript. The two zebrafish SPEG proteins (Spega 
and Spegb) share high sequence conservation with human SPEG, and with both mouse Speg $\alpha$ and $\operatorname{Speg} \beta$ isoforms.

In this study, we investigated the role of SPEG in skeletal muscle development by generating and characterizing multiple zebrafish speg knockout (KO) models (spega-KO, spegb-KO, and spega/spegb double KO zebrafish). A main advantage of the zebrafish model is that zebrafish larvae can survive up to 7 day-post-fertilization (dpf) without a functional heart (Pelster and Burggren, 1996, Stainier, 2001), allowing for skeletal muscle studies even in the setting of impaired cardiac development. We established zebrafish speg KOs using CRISPR/Cas9 directed mutagenesis and confirmed that the resulting mutants exhibited reduced SPEG expression. Phenotypic characterization revealed that speg-DKO mutants effectively recapitulate phenotypes reported in SPEG-related CNM patients, including abnormal triad structure, disrupted calcium dynamics, and impaired skeletal muscle function. Furthermore, similar to other CNM subtypes, we found that SPEG deficiency results in desmin (DES) accumulation and DNM2 upregulation. In total, we established a new zebrafish model suitable for defining the biological role of SPEG in skeletal muscle and for identifying therapies for $S P E G$-related CNM.

\section{Results}

\section{$s p e g b$ is the primary functional SPEG in zebrafish skeletal muscle}

There are two speg genes in zebrafish, spega and spegb. To study tissue expression of spega and $s p e g b$ during development, we performed quantitative RT-PCR (RT-qPCR) on total RNAs extracted from the head region (brain, and predominantly cardiac muscle) or tail region (skeletal muscle) of $2 \mathrm{dpf}$ (day-post-fertilization) and $7 \mathrm{dpf}$ zebrafish wild-type (WT) embryos. We detected similar temporal expression pattern of spega (Fig. 2A) and spegb (Fig. 2B), with significant upregulation observed between $2 \mathrm{dpf}$ to $7 \mathrm{dpf}$ in the head region. We performed whole-mount in situ hybridization to compare spatial expression patterns. We observed spega expression in the brain and developing neural tube, but not the notochord or somites. In contrast, spegb expression was predominantly detected in the chevron-shaped somites (Fig. 2C). These data show that both spega and spegb are expressed from early development, and that zebrafish skeletal muscle predominantly expresses spegb. 


\section{Distinct subcellular localizations of SPEG during early and late muscle development}

To characterize the subcellular localization of SPEG in muscle during development, we stained isolated zebrafish myofibres with a SPEG antibody that recognizes both zebrafish Spega and Spegb proteins. We observed by confocal imaging that Speg is localized to sarcolemmal and perinuclear regions at 2 dpf, with little transverse striations or co-localization with the tSR marker RyR1 (Fig. 2D,D'). However, at $5 \mathrm{dpf}$, Speg loses its early sarcolemmal/perinuclear localization, and instead shows robust transverse co-localization with RyR1 at the triads (Fig. 2E,E'). These results indicate that Speg translocates to the triad junction during muscle development shortly after initial triad formation.

\section{Generation of spega and/or spegb CRISPR/Cas9-mediated knockout lines}

To study SPEG function during development, we used CRISPR/Cas9 to target the two zebrafish speg genes, generating spega or spegb knockout (KO) lines. We designed guide RNAs (gRNAs) and tested their in vivo cutting efficiency using high resolution melting (HRM) analysis (Fig. S1). The most efficient gRNAs were chosen to generate single mutant lines, with double mutant lines later generated by intercrossing F2 single mutants (Fig. 3A). Sanger sequencing confirmed the genotype of one spega mutant as carrying a 10-bp deletion in exon 27 (i.e. spega $\Delta 10$ ), and the genotype of one spegb mutant as carrying a 17-bp deletion in exon 26 (i.e. spegb $\Delta 17$ ), both of which are predicted to introduce premature stop codons in the inter-kinase region (Fig. 3B). To examine the level of speg transcripts, we performed RT-qPCR on total RNA extracted from single mutants, double mutants, and their WT siblings. Although no significant transcript reductions were detected in the single mutants (Fig. S2), we observed significantly decreased spega ( 50\% of WT) and spegb ( $40 \%$ of WT) in spega $\Delta 10$;spegb $\Delta 17$ double mutants (Fig. 3C). Due to lack of Speg antibodies suitable for western blot analysis in zebrafish, we quantified relative protein levels in skeletal muscle by measuring the intensity (gray values) of immunostaining in isolated myofibres (Fig. 3D). We observed that anti-SPEG staining intensity is significantly reduced by $\sim 70 \%$ in spega $\Delta 10$;spegb $\Delta 17$ myofibres when compared to WT, confirming the double mutant zebrafish to be a Speg-deficient zebrafish line, or speg-DKO.

\section{spegb-KO and speg-DKO zebrafish have significantly reduced survival}

We generated single and double knockouts from carrier crosses, and analyzed embryos at the F3 generation and beyond. With the exception of deflated swim bladders in the speg-DKO zebrafish, no obvious morphological abnormalities were noted, with embryos and larvae appearing of normal 
size and without clear bend or curvature to the body shape (Fig. 3E). However, survival was significantly reduced. Using Kaplan-Meier based methodology, we observed that spegb $\Delta 17$ and spega $\Delta$ 10;spegb $\Delta 17$ (or speg-DKO) died at a median age of $10 \mathrm{dpf}$ (Fig. 3F). On the other hand, spega $\Delta 10$ survived to adulthood, and could successfully reproduce.

To validate the specificity of the phenotypes that we observe, we generated additional spega and $s p e g b$ mutant lines, and examined the survival of spega $\Delta 5$;spegb $\Delta 8$, another speg double mutant line. Specifically, we created lines that induce premature stop codons in spega (exon 5, spega $\Delta 5$ )

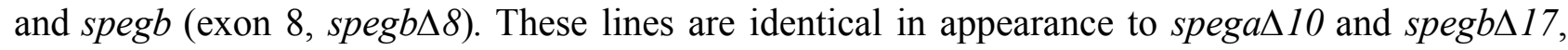
and we observed similar reduced survival rates in spegb $\Delta 8$ and $\operatorname{spega} \Delta 5 ; \operatorname{spegb} \Delta 8$ (Fig. S3). Similarly reduced survival was seen with $\operatorname{speg} b \Delta 8+/$-;spegb $\Delta 17+/$ - compound heterozygotes (data not shown). These data confirm that the phenotypes we describe are due to speg mutation and not to off-target effects. We focused the majority of the remaining analyses on speg-DKO zebrafish, and specifically spega $\Delta 10$;spegb $\Delta 17$, as they best genetically and phenotypically model the human disease.

\section{speg-DKO zebrafish have normal cardiac function}

Patients with SPEG mutations manifest both skeletal muscle and cardiac (e.g. dilated cardiomyopathy) abnormalities, and heart dysfunction could explain the early lethality seen in our speg zebrafish. Therefore, we examined speg-DKO embryos and larvae for signs of cardiac abnormalities. One change associated with cardiomyopathy in zebrafish is pericardial edema, caused by disrupted blood flow and decreased contractile function (Huttner et al., 2018). No evidence of pericardial edema was observed in speg zebrafish. We also did not detect any obvious alterations in heart rate or cardiac rhythm in speg-DKO zebrafish. Therefore, no clear cardiac abnormalities were present in speg-DKO zebrafish, suggesting that the early lethality is due to skeletal muscle dysfunction.

\section{speg deficiency results in alterations in T-tubules and triads}

To determine if speg deficiency leads to skeletal muscle phenotypes that mirror human CNM, we first evaluated the expression pattern of key triad proteins using immunofluorescence (IF) in myofibres isolated from 2 dpf (Fig. 4A-4D) and 5 dpf (Fig. 4A'-4D') WT vs speg-DKOs. In WT myofibres, both RyR1 and DHPR form transverse striations (i.e. triads), as does the sarcomeric Zdisk protein $\alpha$-actinin, while SERCA1 forms both transverse and longitudinal striations reflective of the SR membrane network. In speg-DKO myofibres, however, we observed fragmentation of this 
striated RyR1 and DHPR pattern, with occasional RyR1 mislocalization to the sarcolemma (Fig. 4A), consistent with abnormal early triad development and/or RyR1/DHPR decoupling. To further dissect this, we performed electron microscopic (EM) analyses and found that triad density (the number of triads per $60 \mathrm{\mu m}^{2}$ ) decreased significantly in myofibres from speg-DKO zebrafish (Fig. 4F,F',G), with many triads appearing structurally abnormal (Fig. 4E'). These findings indicate that speg deficiency leads to triad loss/abnormality. Interestingly, transverse, but not longitudinal, SERCA staining is depleted in speg-DKO myofibres from 5 dpf speg-DKO zebrafish (Fig. 4C,C'), while $\alpha$-actinin staining remained normally striated (Fig. 4D,D'), consistent with the normal overall sarcomeric organization observed under EM (Fig. 4E,F). Together, these results indicate that SPEG is essential for triad formation/stability in skeletal muscle.

\section{speg deficiency disrupts ECC and impairs zebrafish swimming performance}

We then set out to examine the effects of speg-DKO on excitation-contraction coupling (ECC) and RyR1 function. ECC was quantified in single myofibres by measuring intracellular calcium dynamics during electrical stimulation and ligand-induced RyR1 $\mathrm{Ca}^{2+}$ release was assessed following local caffeine application. In brief, single myofibres were isolated from genotyped larvae at $7 \mathrm{dpf}$, loaded with $\mathrm{Ca}^{2+}$ sensitive dye (fluo-4AM) (Fig. 5A), and then exposed to a series of electric stimulations (1 Hz, Fig. 5B; and $10 \mathrm{~Hz}$, Fig. 5C,D) followed by 30-second application of 10 $\mathrm{mM}$ caffeine (Fig. 5E). Peak changes of fluo-4 fluorescence (myoplasmic free $\mathrm{Ca}^{2+}$ ) were recorded and normalized to background ( $\Delta$ Ratio). Both myofibres from both spegb-KO (bKO) and spega/bDKO (DKO) zebrafish exhibited significantly reduced electrically-evoked and caffeine-induced $\mathrm{Ca}^{2+}$ release $(\sim 50 \%$ reduction in $\Delta$ Ratio) compared to that observed for myofibres from WT zebrafish (Fig. 5B-5E). These results indicate that speg deficiency results in reduced ECC and RyR1 function in skeletal muscle, consistent with the observed alterations in T-tubules and triads.

To examine whether speg-DKO alters motor performance, we conducted whole zebrafish swimming assays using ZebraBox (Viewpoint, France) (Fig. 5F). As early as 3 dpf, speg-DKO zebrafish traveled significantly less distance (29-49\% reduction) compared to their WT siblings (Fig. 5G). By 7 dpf, speg-DKO zebrafish have a complete absence of movement. Of note, spegb mutants also demonstrated abnormal swim behavior, consistent with $s p e g b$ representing the primary functionally relevant $S P E G$ paralog in skeletal muscle. 


\section{speg-DKO shows abnormal Desmin accumulation and upregulation as early as $5 \mathrm{dpf}$.}

Previous work identified DES (desmin) (Luo et al., 2020) and myotubularin (MTM1) (Agrawal et al., 2014a) as SPEG binding partners in skeletal muscle, and aberrant DES aggregation in Mtm $1 \mathrm{KO}$ mice (Hnia et al., 2011a, Luo et al., 2020). We thus compared DES expression in a series of CNM zebrafish models at stages where muscle phenotypes are fully penetrant: 1) speg-DKO at 5-7 dpf (Figs. 3-5), 2) mtm 1-KO at $7 \mathrm{dpf}$ (Sabha et al., 2016), and 3) DNM2-S619L-eGFP transgenics at 3 dpf (Zhao et al., 2019). To examine DES localization, we stained isolated myofibres with a DES antibody that picks up both Desmin-a and Desmin-b in zebrafish (Kayman Kürekçi et al., 2021). In myofibres from WT zebrafish, DES forms transverse striations marking the sarcomeric Z-disks, and is also localized around the nucleus and below the sarcolemma (Fig. 6A,D). In both speg-DKO (Fig. 6B) and DNM2-S619L (Fig. 6E) this clear striated pattern is lost, and abnormal accumulation is observed longitudinally within the middle of the myofibre and below the sarcolemma. In $\mathrm{mtm} 1$ $\mathrm{KO}$, mild accumulation of DES is observed longitudinally within the middle of the myofibre without an obvious loss of transverse striations (Fig. 6C).

To determine if overall DES expression levels are altered, we performed western blot analysis on whole zebrafish protein lysates. In WT sibling controls (Fig. 6F, 5 dpf; and Fig. 6G, 7 dpf), we observed two DES bands (an upper band $\sim 55 \mathrm{kDa}$ and a lower band $\sim 50 \mathrm{kDa}$ ), consistent with a previous report in adult zebrafish muscle (Kayman Kürekçi et al., 2021). In the mutants, we detected significant DES upregulation in both 5 dpf speg-DKO zebrafish (2-2.5 fold, Fig. 6F') and 7 dpf mtm 1-KO zebrafish (9-12 fold, Fig. 6G') compared to WT controls. Conversely, no difference in DES expression was detected between $3 \mathrm{dpf}$ DNM2-WT and DNM2-S619L zebrafish (Fig. $\left.6 \mathrm{H}, \mathrm{H}^{\prime}\right)$. Of note, only a single DES band at $\sim 55 \mathrm{kDa}$ was observed in the DNM2 experiments, most likely due to the earlier developmental time point ( $3 \mathrm{dpf}$ ) used in these studies. In summary, increased longitudinal DES accumulation was observed across all three models, while increased DES expression was observed only with $5 \mathrm{dpf} s p e g-\mathrm{DKO}$ and $7 \mathrm{dpf} m \mathrm{~mm} 1$-KO zebrafish.

\section{Dnm2 is upregulated and disorganized in skeletal muscle of speg-DKO zebrafish}

Upregulation of endogenous DNM2 protein is a common phenotype observed in non-DNM2-related CNM models including mice lacking Mtm1 (Cowling et al., 2014b) and Bin1 (Cowling et al., 2017b). Thus, we evaluated Dnm2 protein expression in our speg-DKO zebrafish and mtml-KO zebrafish. We first studied Dnm2 localization by performing IF on isolated myofibres using an antibody specifically against zebrafish Dnm2. In WT myofibres (5 dpf), Dnm2 staining appears in 
transverse striations (Fig. 7A). In speg-DKO (Fig. 7B) and mtm1-KO (Fig. 7C), while Dnm2 staining forms similar striated patterns, occasional Dnm2 aggregates can be observed along the striations. However, these patterns are distinct in appearance and localization from the large sarcolemmal DNM2-EGFP aggregates previously observed with DNM2-S619L overexpression (Zhao et al., 2019). To examine Dnm2 protein levels, we performed western blot analysis in 5 dpf speg-DKO (Fig. 7D) and $7 \mathrm{dpf} m t m 1-K O$ (Fig. 7E) zebrafish using whole zebrafish protein lysates. We detected two Dnm2 bands at $\sim 100 \mathrm{kDa}$ in WT siblings, with a significant ( 2-3 fold) increase in the upper band in both speg-DKO (Fig. 7D,D') and mtm1-KO zebrafish (Fig. 7E,E'), consistent with DNM2 upregulation in SPEG- and MTM1-CNM. Together, our results demonstrate that DNM2 is upregulated in SPEG- and MTM1-CNM in the absence of the detectable sarcolemmal DNM2 aggregation seen with DNM2-CNM.

\section{Discussion}

SPEG is a novel CNM-causing gene and the only known kinase associated with CNM. The function of SPEG in skeletal muscle remains unclear. In this study, we provide the first characterization of SPEG in zebrafish. We define the developmental expression of spega/b mRNA, as well as the subcellular localization of SPEG protein in skeletal muscle fibres. We generated single and double knockouts of zebrafish speg paralogs, and show that the double knockout zebrafish exhibit molecular, pathologic, and behavioral phenotypes consistent with the human disease. We also examined potential SPEG-CNM pathomechanisms and therapeutic targets, and found that, as with other forms of CNM, SPEG deficiency is associated with both DES (desmin) accumulation and DNM2 (dynamin 2) upregulation. In all, we establish a new model of SPEG-deficient CNM that will be ideal for studying disease mechanisms and identifying therapies.

There are two speg genes in zebrafish, spega and spegb. Although both share high sequence conservation with human SPEG and are expressed from early zebrafish development, our in situ hybridization data demonstrate that the zebrafish skeletal muscles predominantly express spegb. This is further supported by our loss-of-function data, where spegb single KOs showed similar triad and calcium transient defects as spega/b double knockouts, and also had reduced survival. However, we only detected significantly reduced swimming distance in spega/b double knockouts, suggesting that the lack of both paralogs are required to induce the full muscle phenotype in zebrafish that mirrors that of SPEG-CNM patients. 
Insights into the roles of SPEG during muscle development can be inferred from known SPEG interacting partners identified by yeast two-hybrid and validated in subsequent coimmunoprecipitation experiments, such as Desmin (Luo et al., 2020), and MTM1 (Agrawal et al., 2014b). Desmin is a major intermediate filament protein in muscle that promotes muscle integrity by forming dynamic filamentous networks crosslinking the sarcolemma, sarcomeres, and mitochondria (Paulin and Li, 2004). Emerging evidence has shown that Desmin (DES) is an important CNM disease marker. Abnormal DES accumulation is observed in muscle biopsies from MTM1-CNM and DNM2-CNM patients (Romero and Bitoun, 2011). Speg-deficient mice (Luo et al., 2020), Mtm1-deficient mice (Hnia et al., 2011b), as well as our speg-DKO, mtm1-KO, and DNM2-S619L zebrafish, all show abnormal DES accumulation and/or overall DES upregulation. Although it remains unknown the cause for DES accumulation, reduced/altered DES phosphorylation disrupts intermediate filament disassembly and promote DES accumulation (Winter et al., 2013). Thus it is tempting to speculate that SPEG regulates DES phosphorylation, and that lack of SPEG leads to DES accumulation because of reduced phosphorylation. Future experimentation will be required to test this potential link, and more generally to define substrates of SPEG's kinase activity.

The biological consequences of DES accumulation in SPEG-CNM remain unclear. Notably, DES accumulation has been associated with mitochondrial defects in Mtm1 mouse muscles (Hnia et al., 2011b), and mitochondrial defects along with triad disruption are a key aspect of the CNM disease process (Zanoteli et al., 2009, Lawlor et al., 2016, Muñoz et al., 2020a). It will thus be of interest in the future to examine mitochondrial dynamics in SPEG knockouts. Notably, DES accumulation is also present in desminopathies, a subset of myofibrillar myopathies caused by autosomal dominant DES mutations, which have neither triad defects nor other histopathologic features of CNM, indicating that DES accumulation is unlikely a direct cause for the triad defects observed in CNM. Furthermore, in contrast to desminopathies, we did not observe myofibril dissolution (as indicated by normal $\alpha$-actinin striations) in our CNM zebrafish models, further supporting distinct disease pathways of the two myopathies, consistent with the clinical and histopathological differences between CNM and desminopathy patients.

The triad defects observed in SPEG-CNM are potentially due to disrupted SPEG/MTM1 interaction. MTM1, DNM2, and BIN1 all encode components of the endocytic machinery. Since mutations in each of these genes cause CNM with defective triads, membrane trafficking is 
considered a key aspect of triadogenesis (Dowling et al., 2008). One theory on triad biogenesis is that T-tubule invagination is first initiated by membrane deformation promoted by BIN1 and then completed by DNM2-mediated (Nicot et al., 2007b) membrane fission (Picas et al., 2014, Cowling et al., 2017b). However, the precise roles of SPEG and MTM1 (a phosphatase that acts to dephosphorylate 3-position phosphoinositides (PI[3]P and PI[3,5]P2)) in this pathway are unclear. In Mtm1-KO and Bin1-KO mice, the level of Dnm2 protein is upregulated (Cowling et al., 2014a, Cowling et al., 2017a). In our $m t m l-K O$ and speg-DKO zebrafish, we observed similar increases in Dnm2 protein expression, demonstrating that DNM2 is also upregulated in SPEG-CNM. SPEG/MTM1 interaction therefore may regulate triad biogenesis by regulating DNM2 levels and/or activity. The mechanisms leading to DNM2 upregulation in SPEG-CNM (this study), BIN1(Cowling et al., 2017a), and MTM1-CNM (Cowling et al., 2014a) remain unclear, although lack of BIN1 inhibition (Cowling et al., 2017a), dysregulated microRNA (Liu et al., 2011, Chen et al., 2020), and altered post-translational modifications (e.g. SPEG phosphorylation) (Kusić et al., 2020) have been proposed. Moreover, abnormal DNM2 aggregates are observed (Chin et al., 2015, Zhao et al., 2019) or suggested (Muñoz et al., 2020b) in DNM2-CNM caused by hyperactive DNM2 mutations. However, unlike DNM2-S619L zebrafish (which model DNM2-CNM, we did not observe sarcolemmal Dnm2 aggregates in myofibres from speg-DKO or mtml-KO zebrafish, indicating a level of variability in DNM2 abnormalities across different CNM subtypes. Interestingly, DNM2 reduction has been used as an effective strategy in treating muscle phenotypes of MTM1- and BIN1-CNM mouse models (Tasfaout et al., 2018). It will thus be important to test reducing DNM2 levels (e.g. via genetic ablation, anti-sense oligonucleotides, or manipulating upstream interactions/events) in models of SPEG-CNM.

Given that the subcellular localization of SPEG changes rapidly from being perinuclear/sarcolemmal at $2 \mathrm{dpf}$ to located within the triad junction at $5 \mathrm{dpf}$, SPEG may play distinct roles in developing vs mature muscles. The co-localization of SPEG/RyR1 in mature myofibres suggests that SPEG and RyR1 may interact (similar to SPEG/RyR2 interaction in cardiac muscles) (Quick et al., 2017), such that SPEG promotes phosphorylation events that modulate RyR1 channel function/stability (Jungbluth et al., 2018, Witherspoon and Meilleur, 2016). Of note, it remains unclear how SPEG is recruited to each cellular compartment. Some of these questions could be addressed in future studies that compare RyR1 phosphorylation/interactomes in developing vs mature muscles from WT and speg-DKO zebrafish. Lastly, in the absence of any 
effective treatments for SPEG-CNM, our speg-DKO zebrafish will enable large-scale chemical screens to identify novel small-molecules/pathways to treat the devastating disease.

\section{Conclusions}

In conclusion, we describe the generation and characterization of the first zebrafish model of SPEGCNM. We demonstrate that speg-DKO zebrafish faithfully recapitulate multiple features of SPEGCNM, and identify changes in DES and DNM2 expression/localization as critical (and conserved) disease markers that can be dissected in future studies.

\section{Acknowledgements}

The authors gratefully thank Dr. Yukari Endo for reviewing the manuscript, and Dr. Ramil R Noche for useful discussions and insightful suggestions; Alejandro Salazar, and Elyjah Schimmens for zebrafish maintenance (SickKids Zebrafish Facility); SickKids Imaging facility and SickKids Nanoscale Biomedical Imaging Facility for helps with microscopic training and analysis.

\section{Competing interests}

The authors declare no competing interests.

\section{Funding}

This work was primarily supported by a Canadian Institute of Health Research (CIHR) Rare Disease Models and Mechanisms (RDMM) grant (JJD and ICS). Additional support was from CIHR project scheme operating grant (JJD), NIH R01 AR078000 (to RTD and JJD), and Natural Sciences and Engineering Research Council of Canada (NSERCC) operating grant (JJD).

\section{Author contributions statement}

Conceptualization - KGE, ICS, and JJD. Methodology - KGE, SG, LG, JV, RTD, MZ, and JJD. Validation - KGE, SG, LG, MZ, and JJD. Formal analysis - KGE, SG, LG, ICS, RTD, MZ, and JJD. Investigation - KGE, SG, LG, JV, and MZ. Visualization - KGE, SG, and MZ. Resources RTD and JJD. Writing (Original Draft Preparation) - KGE. Writing (Review \& Editing) - KGE, SG, LG, ICS, RTD, MZ, and JJD. Supervision - ICS, RTD, MZ, and JJD. Project administration$\mathrm{MZ}$ and JJD. Funding acquisition - ICS, RTD, and JJD. 


\section{Materials and Methods}

\section{Zebrafish maintenance}

Zebrafish (AB strain) were raised and maintained at $28.5^{\circ} \mathrm{C}$ at the Zebrafish Facility at the Hospital for Sick Children, Toronto, ON, Canada. Experiments were performed on zebrafish embryos and larvae from the one-cell stage up to $15 \mathrm{dpf}$. All zebrafish procedures were performed in strict accordance with the Animals for Research Act of Ontario and the Guidelines of the Canadian Council on Animal Care.

\section{Quantitative Real-Time PCR (RT-qPCR)}

Total mRNA was isolated from 2 dpf or 7 dpf zebrafish homogenates using the RNeasy Mini Kit (Qiagen, Cat\# 74104) and reverse-transcribed with SuperScript VILO (ThermoFisher, Cat\# 11755050). Approximately, 10-25 embryos were collected for each condition, in triplicates. Head and trunk dissections were done to cut at the region indicated at the diagram (Fig. S4). RT-qPCR was performed using Platinum SYBR Green reagent (ThermoFisher, Cat\# 11744500) and the StepOne-Plus Real-Time PCR System (Applied Biosystems). All reactions were performed in technical triplicates and the results represent biological triplicates. The zebrafish peptidylprolyl isomerase B gene, ppib, was used as the endogenous control. Primers used are as follows: spega forward 5'ACAAAGAGATTGGCAGAGGGG-3', reverse 5'-ACTCTCGCAATGCACAAGTC3'; spegb forward 5'-CAACAACAAGTACGGCAGCG-3', reverse 5 TGCAAATCGAGGAGTCTCGC-3'; and ppib forward 5'-ACCCAAAGTCACGGCTAAGG-3', reverse 5'-CTGTGGTTTTAGGCACGGTC-3'. Protocol Conditions for RT-qPCR are the following: $95^{\circ} \mathrm{C} 10^{\prime} \rightarrow\left(95^{\circ} \mathrm{C} 15^{\prime \prime} \rightarrow 60^{\circ} \mathrm{C} 1^{\prime}\right)(\mathrm{x} 40$ cycles $) \rightarrow\left[95^{\circ} \mathrm{C} 15^{\prime \prime} \rightarrow 60^{\circ} \mathrm{C} 1\right.$ $\left.\rightarrow 95^{\circ} \mathrm{C} 15^{\prime}\right]$ [Melt Curve].

\section{Wholemount in-situ hybridization (ISH)}

Probes were generated via PCR amplification from 2 dpf total cDNA synthesis using SuperScript VILO (ThermoFisher, Cat\# 11755050). Primers used were as follows: spega forward 5'-AAGAAGCAAGCTCACCCACA-3', reverse 'AAGTCAAGGTCTGTCGACGC-3'; spegb forward 5'-CGAAACTCACACGGGGAAGA3', reverse 5'-GACTGTGATGCTCAAGGGCT-3'. DIG-labeled in-situ probes were synthesized using DIG RNA Labeling kits (Roche, Cat\# 11277073910). RNA in-situ hybridization was carried out as previously described (Thisse and Thisse, 2007). Briefly, embryos were fixed in $4 \%$ paraformaldehyde (PFA) and then dehydrated in 100\% Methanol. Embryos were then 
permeabilized and incubated with digoxigenin-labeled antisense RNA probes at a final concentration of $300 \mathrm{ng} / 200 \mu \mathrm{L}$ in hybridization solution. Hybridizations of the probe with the RNA were detected with an alkaline phosphatase-conjugated antibody (Anti-Digoxigenin-AP, Fab Fragments, 1:5000, Roche, Cat\# 11093274910). Finally, stained embryos were cleared overnight in a $70 \%$ glycerol solution with 30\% PBSTw (0.1\% Tween 20 in PBS), and imaged under a Leica M205FA stereomicroscope.

\section{Generation of zebrafish speg mutants}

The program Chopchop (http://chopchop.cbu.uib.no/) (Montague et al., 2014) was used to design each of the guide RNAs (gRNAs) used in this project. According to Chopchop, there were no predicted off-targets for the gRNAs tested. Next, 50 to 100 one-cell stage WT embryos were injected with the gRNA (150pg per embryo) and Cas9 mRNA (100pg per embryo) with a Picopump (World Precision Instruments). Strong gRNAs were identified by isolating genomic DNA from 24 individual injected embryos and 3 uninjected embryos at 3-5 dpf. DNA was digested with $1 \mu \mathrm{g} / \mu \mathrm{l}$ Proteinase $\mathrm{K}$ and all embryos were genotyped using HRM analysis and Sanger Sequencing. HRM analysis was performed on a Roche Lightcycler 96. Once we identified gRNAs that were cutting at the desired genomic region, potential founders (F0) were outcrossed to WT AB zebrafish. In-cross progeny from the F3 and F4 generations were used for the characterization of the spegmutant phenotype. The targets in this study were: spega 5'CTATCGACCTGGACCTGTAGG-3' at exon 27, and spegb 5'ATGGCTCTCGCTTAGGGGAGG-3' at exon 26. Primers used for HRM are as follows: spegas10 at exon 27 forward 5'-AAGAAAGCTCACCGGTTCCC-3', reverse 5'TGGACAGACTTGGATTTTTCCT-3'; and spegb 17 at exon 26 forward 5'CCCTCCCAAAGAGCCAAGTC-3', reverse 5'-GCGAGCTTCAAAAACCTCCT-3'. Primers used for PCR prior to Sanger sequencing are as follows: spega 10 forward 5'ACACCATTACCGACACCAGTT-3', reverse 5'-TACGTCGCACTGCAAGGAC-3'; and spegb $\Delta 17$ forward 5'-TCTTTTCTCGGGTTGCCTCC-3', $\quad$ reverse 5'GAGAGTCGCCTCATGAACCC-3’.

\section{Morphological assessment and survival analysis.}

Fish were examined daily for morphological abnormalities, and imaged at 6 dpf using Zeiss Axio Zoom V16 microscope (16x, 10 ms exposure). Survival analysis was performed using KaplanMeier methods. Briefy, 3-5 dpf larvae were fin clipped and then grouped by genotype after HRM 
analysis. Survival count and health check was performed daily until they reached adulthood. The number of live embryos was plotted across time and analyzed using GraphPad Prism version 8 (GraphPad Software).

\section{Immunofluorescence staining on isolated myofibres and quantification}

Skeletal myofibres from WT and speg-KO were isolated as previously described (Horstick et al., 2013). Briefly, embryos at each respective time point were digested with collagenase type II (LS004176, Worthington Biochemical Corporation) and plated on $12 \mathrm{~mm}$ circular coverslips. Samples were then fixed with $4 \%$ PFA for $20 \mathrm{~min}$ at room temperature or $100 \%$ Methanol for 10 min at $4^{\circ} \mathrm{C}$, permeabilized with $1 \mathrm{XPBSTw}(0.1 \%$ Tween 20 in PBS), incubated with blocking solution $(0.2 \%$ TritonX-100, 0.2\% BSA, 5\% Goat Serum in PBS) for $30 \mathrm{~min} \sim 1 \mathrm{hr}$ at room temperature, and then incubated with primary antibodies overnight at $4^{\circ} \mathrm{C}$. Samples were stained in the dark with secondary antibodies for $1 \mathrm{hr}$ at room temperature, and mounted with ProLong Gold Antifade Mountant (Invitrogen). Sample slides were dried at room temperature overnight in dark and stored in $4^{\circ} \mathrm{C}$ until imaging. Images were taken using a Leica SP8 Lightning Confocal microscope. The primary antibodies used were: rabbit polyclonal anti-SPEG (1:100; PA553875, Invitrogen), mouse monoclonal anti-RyR1 (1:100; 34C, DSHB), rabbit polyclonal antiCACNA1S (1:100; ab203662, Abcam; which labels the DHPR protein), mouse monoclonal antiSERCA1a (1:200; ab2819; Abcam), rabbit polyclonal anti-DES (1:100; D8281, Sigma), rabbit polyclonal anti-DNM2 (1:100; GTX127330; GeneTex), and mouse monoclonal anti- $\alpha$-actinin (1:100; A7811; Sigma). The secondary antibodies used were anti-rabbit Alexa Fluor ${ }^{\circledR} 488$ (1:300, Invitrogen), and anti-mouse Alexa Flour ${ }^{\circledR} 594$ (1:300, Invitrogen).

To quantify immunofluorescence intensity, all Z-stack images were taken with the same microscope settings (i.e. objective, laser power, intensity, zoom, pixel size, and scanning speed). At least three fibres were imaged per group (WT or mutant) per myofibre prep immunostaining experiment, and three independent experiments were performed. For each image, average projection was generated using Fiji ImageJ, gray value was measured for signals (average of 3 measurements within the fibre) vs backgrounds (average of 3 measurements outside the fibre) using the square tool (area specified as $25 \mu \mathrm{m} \times 8 \mu \mathrm{m}$ ), and background value was subtracted from signal. The means of background-subtracted signals per group per experiment were plotted in GraphPad Prism version 8 (GraphPad Software), and compared using Student's $t$-test. 


\section{Transmission electron microscopy (TEM)}

7 dpf larvae were anaesthetized using $0.1 \%$ tricaine and fixed in Karnovsky's fixative [2.5\% glutaraldehyde (GA) / 2\% PFA in 0.1M cacodylate buffer, $\mathrm{pH} 7.5$ ] at room temperature for 2 hrs, and re-fixed in fresh fixatives overnight at $4^{\circ} \mathrm{C}$. The samples were then washed $3 \times 5$ min in $0.1 \mathrm{M}$ cacodylate buffer ( $\mathrm{pH} 7.5$ ), post-fixed in $1 \%$ osmium (in $0.1 \mathrm{M}$ cacodylate buffer, $\mathrm{pH} 7.5$ ) for $1.5 \mathrm{hr}$ at room temperature, and washed $3 \times 5 \mathrm{~min}$ with $0.1 \mathrm{M}$ cacodylate buffer. Samples were then dehydrated with serial ethanol washes $(70 \%, 90 \%, 95 \%$, and 100\%), infiltrated with Epon, and embedded in Epon to let polymerize in a $60^{\circ} \mathrm{C}$ oven for $24-48 \mathrm{hrs}$. Semi-thin $(1 \mu \mathrm{m})$ and ultra-thin (90 nm) sections were cut using Leica Ultracut ultramicrotomes and transferred on $200 \mathrm{~nm}$ copper grids. Grids were post-stained with 2\% uranyl acetate at room temperature for $20 \mathrm{~min}$, washed 7x 1 min with MilliQ water, and stained with lead citrate for $5 \mathrm{~min}$, followed by $7 \mathrm{x} 1 \mathrm{~min}$ water wash. Samples were imaged using FEI Tecnai 20 transmission electron microscope.

\section{Measurement of electrically-evoked and caffeine-induced $\mathrm{Ca}^{2+}$ release in dissociated myofibres}

For all experiments, individual myofibres were isolated by enzymatic digestions and then loaded with $5 \mu \mathrm{M}$ fluo-4AM (Molecular Probes) for $45 \mathrm{~min}$ at room temperature in a normal rodent Ringer's solution consisting of (in mM): $145 \mathrm{NaCl}, 5 \mathrm{KCl}, 2 \mathrm{CaCl}_{2}, 1 \mathrm{MgCl}_{2}, 10 \mathrm{HEPES}, \mathrm{pH}$ 7.4. Fibres were then transferred to dye-free rodent Ringer's solution supplemented with $25 \mu \mathrm{m}$ Nbenzyl p-toluene sulfonamide (BTS) for $20 \mathrm{~min}$ at room temperature to block contractions. Fluo4loaded fibres were excited at $480 \pm 15 \mathrm{~nm}$ and fluorescence emission detected at $535 \pm 20 \mathrm{~nm}$ was collected at $10 \mathrm{kHz}$ using a photomultiplier system. Myoplasmic $\mathrm{Ca}^{2+}$ transients in fluo4-loaded myofibres were stimulated by an electrical field stimulation protocol using a glass electrode filled with $200 \mathrm{mM} \mathrm{NaCl}$ placed adjacent to the cell of interest. The stimulation protocol consisted of five twitch stimuli delivered at $1 \mathrm{~Hz}$ followed by a single $5 \mathrm{sec}, 10 \mathrm{~Hz}$ stimulation train, and then exposure to $10 \mathrm{mM}$ caffeine for $30 \mathrm{sec}$ in the absence of electrical stimulation. Peak change in fluo4 fluorescence was measured and expressed as $\left(\mathrm{F}_{\max }-\mathrm{F}_{0}\right) / \mathrm{F}_{0}$.

\section{Swimming assay and muscle performance quantification}

To quantify muscle performance, $3 \mathrm{dpf}$ and $5 \mathrm{dpf}$ zebrafish were individually transferred to a 96well plate and incubated in an optovin analog $6 \mathrm{~b} 8(10 \mu \mathrm{M}$ in $200 \mu \mathrm{L}$ of embryo water, ChemBridge, Cat\# 5707191) at $28.5^{\circ} \mathrm{C}$ for $5 \mathrm{~min}$ in the dark. Motor activity of the larvae was recorded and analyzed using ZebraBox (Viewpoint, France) as previously described (Zhao et al., 
2019) with $30 \mathrm{sec}$ light on, 1 min light off, $30 \mathrm{sec}$ light on, 1 min light off, and $30 \mathrm{sec}$ light on. Four independent experiments were conducted including WT vs speg-KO embryos, and n=24 larvae per group. Total distance travelled ( $\mathrm{mm}$ ) was plotted and analyzed using GraphPad Prism version 8 (GraphPad Software). Standard error of the mean (SEM) was calculated for each group, and oneway ANOVA was performed to test statistical significance.

\section{Protein extraction}

Embryos were fin clipped at 3-4 dpf and genotyped using HRM analysis as described above. 5 dpf WT or speg-KO embryos were collected ( 20 embryos per group) and immediately stored at $-80^{\circ} \mathrm{C}$. Samples were homogenized using a Pellet Mixer (VWR, Cat\# 47747-370) in 1X RIPA buffer (Cell Signaling, Cat\# 9806) supplemented with Complete Mini EDTA-free Protease inhibitor tablets (46548400, Roche, $1 / 2$ tablet per $5 \mathrm{~mL}$ lysis buffer) and phosphatase inhibitors (CA80501-130, VMR, 1:100). Lysates were chilled at $4^{\circ} \mathrm{C}$ for $10 \mathrm{~min}$, sonicated and centrifuged at $12,000 \times \mathrm{g}$ for $30 \mathrm{~min}$ at $4^{\circ} \mathrm{C}$. Supernatants were collected, and protein concentration quantified using the Pierce $\mathrm{TM}^{\mathrm{TM}}$ BCA protein assay kit (Cat\# 23225, Thermo zebrafisher Scientific).

\section{Western Blot}

Protein lysates (40 $\mu \mathrm{g} / \mathrm{lane}$ ) were mixed with LDS sample buffer X4 (Invitrogen, B0007, X1) /DTT $(100 \mathrm{mM})$ and boiled at $95^{\circ} \mathrm{C}$ for $5 \mathrm{~min}$ before loading. Samples were run at $100 \mathrm{~V}$, transferred using semi-dry transfer at $10 \mathrm{~V}$ for $70 \mathrm{~min}$ and resolved on PVDF membranes. Equal loading and transfer efficiency were assessed by total protein (REVERT ${ }^{\mathrm{TM}} 700$, Li-cor) staining prior to blocking. Membranes were blocked in 1X TBST containing 3\% bovine serum albumin (BSA) for 1$2 \mathrm{hrs}$ at room temperature, and then incubated overnight at $4{ }^{\circ} \mathrm{C}$ with primary antibody in blocking solution. Membranes were washed and probed with secondary antibody (1:5000, anti-Rabbit-HRP, 1706515; anti-Mouse-HRP 1706516, BioRad) in blocking solution. Blots were imaged by chemiluminescence (Clarity Max ${ }^{\mathrm{TM}} \mathrm{ECL}$, BioRad) using the Gel Doc ${ }^{\mathrm{TM}} \mathrm{XR}+\mathrm{Gel}$ Documentation System (BioRad). Band signal intensities were determined using Fiji ImageJ software. All densitometry values are individually standardized to corresponding values of total protein stain and expressed as the fold difference from the average of the WT group of each blot. Primary antibodies used: anti-DES (1:1000; D8281, Sigma), anti-beta-actin (1:1000, 8226, Abcam), and Dnm2 (1:1000; GTX127330; GeneTex). 


\section{Statistics}

Post-capture analysis, including tests of statistical significance, was performed using Microsoft Excel 2016 (Microsoft) and GraphPad Prism version 8 (GraphPad Software). The difference between three or more groups was assessed by ordinary one-way ANOVA followed by Tukey's multiple comparisons test. The difference between two groups was assessed by 2-tailed Student's $t$ test or by 2-tailed Mann-Whitney test. All survival curves were assessed by Mantel-Cox test. Differences were considered to be statistically significant if $* P<0.05,{ }^{*} P<0.01,{ }^{*} * *<0.001$, or $* * * * P<0.0001$. All data unless otherwise specified are presented as mean \pm SEM. 


\section{References}

AGRAWAL, P. B., PIERSON, C. R., JOSHI, M., LIU, X., RAVENSCROFT, G., MOGHADASZADEH, B., TALABERE, T., VIOLA, M., SWANSON, L. C., HAliloglu, G., TAlim, B., YAU, K. S., AllCOCK, R. J., LAING, N. G., PERRELLA, M. A. \& BEGGS, A. H. 2014a. SPEG interacts with myotubularin, and its deficiency causes centronuclear myopathy with dilated cardiomyopathy. Am J Hum Genet, 95, 218-26.

AGRAWAL, P. B., PIERSON, C. R., JOSHI, M., LIU, X., RAVENSCROFT, G., MOGHADASZADEH, B., TALABERE, T., VIOLA, M., SWANSON, L. C., HAliloĞlU, G., TAlim, B., YAU, K. S., AllCOCK, R. J., LAING, N. G., PERRELLA, M. A. \& BEGGS, A. H. 2014b. SPEG interacts with myotubularin, and its deficiency causes centronuclear myopathy with dilated cardiomyopathy. American journal of human genetics, 95, 218-226.

AL-QUSAIRI, L. \& LAPORTE, J. 2011. T-tubule biogenesis and triad formation in skeletal muscle and implication in human diseases. Skeletal Muscle, 1, 26.

ALMANNAI, M., LUO, S., FAQEIH, E., AL MUTAIRI, F., LI, Q. \& AGRAWAL, P. B. 2021. Homozygous

\section{SPEG}

Mutation Is Associated With Isolated Dilated Cardiomyopathy. Circulation: Genomic and Precision Medicine, 14.

AMBURGEY, K., MCNAMARA, N., BENNETT, L. R., MCCORMICK, M. E., ACSADI, G. \& DOWLING, J. J. 2011. Prevalence of congenital myopathies in a representative pediatric united states population. Annals of Neurology, 70, 662-665.

Bitoun, M., MAUGEnRE, S., JEANNET, P.-Y., LACÈNE, E., FERRER, X., LAFORÊT, P., MARTIN, J.-J., LAPORTE, J., LOCHMÜLLER, H., BEGGS, A. H., FARDEAU, M., EYMARD, B., ROMERO, N. B. \& GUICHENEY, P. 2005. Mutations in dynamin 2 cause dominant centronuclear myopathy. Nature Genetics, 37, 1207-1209.

CASWELL, A. H., MOTOIKE, H. K., FAN, H. \& BRANDT, N. R. 1999. Location of ryanodine receptor binding site on skeletal muscle triadin. Biochemistry, 38, 90-97.

CHEN, X., GAO, Y.-Q., ZHENG, Y.-Y., WANG, W., WANG, P., LIANG, J., ZHAO, W., TAO, T., SUN, J., WEI, L., LI, Y., ZHOU, Y., GAN, Z., ZHANG, X., CHEN, H.-Q. \& ZHU, M.S. 2020. The intragenic microRNA miR199A1 in the dynamin 2 gene contributes to the 
pathology of X-linked centronuclear myopathy. Journal of Biological Chemistry, 295, 86568667.

CHIN, Y.-H., LEE, A., KAN, H.-W., LAIMAN, J., CHUANG, M.-C., HSIEH, S.-T. \& LIU, Y.-W. 2015. Dynamin-2 mutations associated with centronuclear myopathy are hypermorphic and lead to T-tubule fragmentation. Human Molecular Genetics, 24, 5542-5554.

CONLON, F. L., LEVITAS, A., MUHAMMAD, E., ZHANG, Y., PEREA GIL, I., SERRANO, R., DIAZ, N., ARAFAT, M., GAVIDIA, A. A., KAPILOFF, M. S., MERCOLA, M., ETZION, Y., PARVARI, R. \& KARAKIKES, I. 2020. A Novel Recessive Mutation in SPEG Causes Early Onset Dilated Cardiomyopathy. PLOS Genetics, 16, e1009000.

COSTEllo, B., CHADWICK, C., SAITO, A., CHU, A., MAURER, A. \& FLEISCHER, S. 1986. Characterization of the junctional face membrane from terminal cisternae of sarcoplasmic reticulum. The Journal of Cell Biology, 103, 741-753.

COWling, B. S., CHEVREMONT, T., PROKIC, I., KRETZ, C., FERRY, A., COIRAUlt, C., KOUTSOPOULOS, O., LAUGEL, V., ROMERO, N. B. \& LAPORTE, J. 2014a. Reducing dynamin 2 expression rescues X-linked centronuclear myopathy. Journal of Clinical Investigation, 124, 1350-1363.

COWling, B. S., CHEVREMONT, T., PROKIC, I., KRETZ, C., FERRY, A., COIRAUlt, C., KOUTSOPOULOS, O., LAUGEL, V., ROMERO, N. B. \& LAPORTE, J. 2014b. Reducing dynamin 2 expression rescues X-linked centronuclear myopathy. J Clin Invest, 124, 135063.

COWling, B. S., PROKIC, I., TASFAOUT, H., RABAI, A., HUMBERT, F., RINALDI, B., NICOT, A.-S., KRETZ, C., FRIANT, S., ROUX, A. \& LAPORTE, J. 2017a. Amphiphysin (BIN1) negatively regulates dynamin 2 for normal muscle maturation. Journal of Clinical Investigation, 127, 4477-4487.

COWling, B. S., PROKIC, I., TASFAOUT, H., RABAI, A., HUMBERT, F., RINALDI, B., NICOT, A. S., KRETZ, C., FRIANT, S., ROUX, A. \& LAPORTE, J. 2017b. Amphiphysin (BIN1) negatively regulates dynamin 2 for normal muscle maturation. J Clin Invest, 127, 4477-4487.

DOWLING, J. J., GIBBS, E. M. \& FELDMAN, E. L. 2008. Membrane traffic and muscle: lessons from human disease. Traffic, 9, 1035-43.

DOWLING, J. J., WEIHL, C. C. \& SPENCER, M. J. 2021. Molecular and cellular basis of genetically inherited skeletal muscle disorders. Nat Rev Mol Cell Biol. 
FLEMING, J. R., RANI, A., KRAFT, J., ZENKER, S., BÖRGESON, E. \& LANGE, S. 2021. Exploring Obscurin and SPEG Kinase Biology. Journal of Clinical Medicine, 10, 984.

GONORAZKY, H. D., BÖNNEMANN, C. G. \& DOWLING, J. J. 2018. The genetics of congenital myopathies. Handbook of clinical neurology, 148, 549-564.

GOONASEKERA, S. A., BEARD, N. A., GROOM, L., KIMURA, T., LYFENKO, A. D., ROSENFELD, A., MARTY, I., DULHUNTY, A. F. \& DIRKSEN, R. T. 2007. Triadin Binding to the C-Terminal Luminal Loop of the Ryanodine Receptor is Important for Skeletal Muscle Excitation-Contraction Coupling. Journal of General Physiology, 130, 365-378.

GROH, S., MARTY, I., OTTOLIA, M., PRESTIPINO, G., CHAPEL, A., VILlAZ, M. \& RONJAT, M. 1999. Functional Interaction of the Cytoplasmic Domain of Triadin with the Skeletal Ryanodine Receptor. Journal of Biological Chemistry, 274, 12278-12283.

GUO, W. \& CAMPBELL, K. P. 1995. Association of Triadin with the Ryanodine Receptor and Calsequestrin in the Lumen of the Sarcoplasmic Reticulum. Journal of Biological Chemistry, 270, 9027-9030.

HNIA, K., TRONCHERE, H., TOMCZAK, K. K., AMOASII, L., SCHUlTZ, P., BEGGS, A. H., PAYRASTRE, B., MANDEL, J. L. \& LAPORTE, J. 2011a. Myotubularin controls desmin intermediate filament architecture and mitochondrial dynamics in human and mouse skeletal muscle. J Clin Invest, 121, 70-85.

HNIA, K., TRONCHÈRE, H., TOMCZAK, K. K., AMOASII, L., SCHUlTZ, P., BEGGS, A. H., PAYRASTRE, B., MANDEL, J. L. \& LAPORTE, J. 2011b. Myotubularin controls desmin intermediate filament architecture and mitochondrial dynamics in human and mouse skeletal muscle. Journal of Clinical Investigation, 121, 70-85.

HORSTICK, E. J., GIBBS, E. M., LI, X., DAVIDSON, A. E. \& DOWLING, J. J. 2013. Analysis of embryonic and larval zebrafish skeletal myofibers from dissociated preparations. Journal of visualized experiments : JoVE.

HSIEH, C.-M., FUKUMOTO, S., LAYNE, M. D., MAEMURA, K., CHARLES, H., PATEL, A., PERRELLA, M. A. \& LEE, M.-E. 2000. Striated Muscle Preferentially Expressed Genes $\alpha$ and $\beta$ Are Two Serine/Threonine Protein Kinases Derived from the Same Gene as the Aortic Preferentially Expressed Gene-1. Journal of Biological Chemistry, 275, 36966-36973.

HUNTOON, V., WIDRICK, J. J., SANCHEZ, C., ROSEN, S. M., KUTCHUKIAN, C., CAO, S., PIERSON, C. R., LIU, X., PERRELlA, M. A., BEGGS, A. H., JACQUEMOND, V. \& 
AGRAWAL, P. B. 2018. SPEG-deficient skeletal muscles exhibit abnormal triad and defective calcium handling. Human Molecular Genetics, 27, 1608-1617.

HUTTNER, I. G., WANG, L. W., SANTIAGO, C. F., HORVAT, C., JOHNSON, R., CHENG, D., VON FRIELING-SALEWSKY, M., HILLCOAT, K., BEMAND, T. J., TRIVEDI, G., BRAET, F., HESSELSON, D., ALFORD, K., HAYWARD, C. S., SEIDMAN, J. G., SEIDMAN, C. E., FENELEY, M. P., LINKE, W. A. \& FATKIN, D. 2018. A-Band Titin Truncation in Zebrafish Causes Dilated Cardiomyopathy and Hemodynamic Stress Intolerance. Circulation: Genomic and Precision Medicine, 11.

JUNGBluth, H., TREVES, S., ZORZATO, F., SARKOZY, A., OCHALA, J., SEWRY, C., PHADKE, R., GAUTEL, M. \& MUNTONI, F. 2018. Congenital myopathies: disorders of excitation-contraction coupling and muscle contraction. Nature Reviews Neurology, 14, 151-167.

JUNGBLUTH, H., WALLGREN-PETTERSSON, C. \& LAPORTE, J. 2008. Centronuclear (myotubular) myopathy. Orphanet Journal of Rare Diseases, 3, 26.

KAYMAN KÜREKÇI, G., KURAL MANGIT, E., KOYUNLAR, C., UNSAL, S., SAGLAM, B., ERGIN, B., GIZER, M., UYANIK, I., BOUSTANABADIMARALAN DÜZ, N., KORKusuZ, P., TAliM, B., PURAli, N., HUGHES, S. M. \& DINCER, P. R. 2021. Knockout of zebrafish desmin genes does not cause skeletal muscle degeneration but alters calcium flux. Scientific Reports, 11, 7505.

KUSiĆ, D., CONNOlly, J., KAinulainen, H., SEMENOVA, E. A., BORISOV, O. V., LARIN, A. K., POPOV, D. V., GENEROZOV, E. V., AHMETOV, I. I., BRITTON, S. L., KOCH, L. G. \& BURNISTON, J. G. 2020. Striated muscle-specific serine/threonine-protein kinase beta segregates with high versus low responsiveness to endurance exercise training. Physiological Genomics, 52, 35-46.

LAPORTE, J., HU, L. J., KRETZ, C., MANDEL, J.-L., KIOSCHIS, P., COY, J. F., KLAUCK, S. M., POUSTKA, A. \& DAHL, N. 1996. A gene mutated in X-linked myotubular myopathy defines a new putative tyrosine phosphatase family conserved in yeast. Nature Genetics, 13, 175-182.

LAWlor, M. W., BEGGS, A. H., BUJ-BEllo, A., CHILDERS, M. K., DOWLing, J. J., JAMES, E. S., MENG, H., MOORE, S. A., PRASAD, S., SCHOSER, B. \& SEWRY, C. A. 2016. Skeletal Muscle Pathology in X-Linked Myotubular Myopathy: Review With CrossSpecies Comparisons. Journal of Neuropathology \& Experimental Neurology, 75, 102-110. 
LIU, N., BEZPROZVANNAYA, S., SHELTON, J. M., FRISARD, M. I., HULVER, M. W., MCMILlAN, R. P., WU, Y., VOELKER, K. A., GRANGE, R. W., RICHARDSON, J. A., BASSEL-DUBY, R. \& OLSON, E. N. 2011. Mice lacking microRNA 133a develop dynamin 2-dependent centronuclear myopathy. Journal of Clinical Investigation, 121, 3258-3268.

LIU, W., XIE, Y., MA, J., LUO, X., NIE, P., ZUO, Z., LAHRMANN, U., ZHAO, Q., ZHENG, Y., ZHAO, Y., XUE, Y. \& REN, J. 2015. IBS: an illustrator for the presentation and visualization of biological sequences: Fig. 1. Bioinformatics, 31, 3359-3361.

LIU, X., RAMJIGANESH, T., CHEN, Y.-H., CHUNG, S. W., HALL, S. R., SCHISSEL, S. L., PADERA, R. F., LIAO, R., ACKERMAN, K. G., KAJSTURA, J., LERI, A., ANVERSA, P., YET, S.-F., LAYNE, M. D. \& PERRELlA, M. A. 2009. Disruption of Striated Preferentially Expressed Gene Locus Leads to Dilated Cardiomyopathy in Mice. Circulation, 119, 261-268.

LORNAGE, X., SABOURAUD, P., LANNES, B., GAILLARD, D., SCHNEIDER, R., DELEUZE, J.-F., BOLAND, A., THOMPSON, J., BÖHM, J., BIANCALANA, V. \& LAPORTE, J. 2018. Novel SPEG Mutations in Congenital Myopathy without Centralized Nuclei. Journal of Neuromuscular Diseases, 5, 257-260.

LOUIS, E. D., MAYER, S. A. \& NOBLE, J. M. 2022. Merritt's neurology, Philadelphia, Wolters Kluwer.

LUO, S., LI, Q., LIN, J., MURPHY, Q., MARTY, I., ZHANG, Y., KAZEROUNIAN, S. \& AGRAWAL, P. B. 2020. SPEG binds with desmin and its deficiency causes defects in triad and focal adhesion proteins. Human Molecular Genetics, 29, 3882-3891.

MOnTAgue, T. G., CRUZ, J. M., GAGnON, J. A., CHURCH, G. M. \& VALEN, E. 2014. CHOPCHOP: a CRISPR/Cas9 and TALEN web tool for genome editing. Nucleic Acids Research, 42, W401-W407.

MUÑOZ, X., KRETZ, C., SILVA-ROJAS, R., OCHALA, J., MENUET, A., ROMERO, N. B., COWLING, B. S. \& LAPORTE, J. 2020a. Physiological impact and disease reversion for the severe form of centronuclear myopathy linked to Dynamin. JCI insight.

MUÑOZ, X. M., KRETZ, C., SILVA-ROJAS, R., OCHALA, J., MENUET, A., ROMERO, N. B., COWLING, B. S. \& LAPORTE, J. 2020b. Physiological impact and disease reversion for the severe form of centronuclear myopathy linked to dynamin. JCI Insight, 5.

NANCE, J. R., DOWLING, J. J., GIBBS, E. M. \& BÖNNEMANN, C. G. 2012. Congenital Myopathies: An Update. Current Neurology and Neuroscience Reports, 12, 165-174. 
NICOT, A.-S., TOUSSAINT, A., TOSCH, V., KRETZ, C., WALlGREN-PETTERSSON, C., IWARSSON, E., KINGSTON, H., GARNIER, J.-M., BIANCALANA, V., OLDFORS, A., MANDEL, J.-L. \& LAPORTE, J. 2007a. Mutations in amphiphysin 2 (BIN1) disrupt interaction with dynamin 2 and cause autosomal recessive centronuclear myopathy. Nature Genetics, 39, 1134-1139.

NiCOT, A. S., TOUSSAINT, A., TOSCH, V., KRETZ, C., WALlGREN-PETTERSSON, C., IWARSSON, E., KINGSTON, H., GARNIER, J. M., BIANCALANA, V., OLDFORS, A., MANDEL, J. L. \& LAPORTE, J. 2007b. Mutations in amphiphysin 2 (BIN1) disrupt interaction with dynamin 2 and cause autosomal recessive centronuclear myopathy. Nature genetics, 39, 1134-9.

PARK, H., PARK, I. Y., KIM, E., YOUN, B., FIELDS, K., DUNKER, A. K. \& KANG, C. 2004. Comparing Skeletal and Cardiac Calsequestrin Structures and Their Calcium Binding. Journal of Biological Chemistry, 279, 18026-18033.

PAULIN, D. \& LI, Z. 2004. Desmin: a major intermediate filament protein essential for the structural integrity and function of muscle. Experimental Cell Research, 301, 1-7.

PELSTER, B. \& BURGGREN, W. W. 1996. Disruption of Hemoglobin Oxygen Transport Does Not Impact Oxygen-Dependent Physiological Processes in Developing Embryos of Zebra Fish (Danio rerio). Circulation research.

PICAS, L., VIAUD, J., SCHAUER, K., VANNI, S., HNIA, K., FRAISIER, V., ROUX, A., BASSEREAU, P., GAITS-IACOVONI, F., PAYRASTRE, B., LAPORTE, J., MANNEVILLE, J. B. \& GOUD, B. 2014. BIN1/M-Amphiphysin2 induces clustering of phosphoinositides to recruit its downstream partner dynamin. Nat Commun, 5, 5647.

QUAlls, A. E., DONKERVOORT, S., HERKERT, J. C., D'GAMA, A. M., BHARUCHAGOEBEl, D., COllins, J., CHAO, K. R., FOlEY, A. R., SCHOOTS, M. H., JONGBlOED, J. D. H. D. H., BÖNNEMANN, C. G. \& AGRAWAL, P. B. 2019. Novel SPEG mutations in congenital myopathies: Genotype-phenotype correlations. Muscle \& nerve, 59, 357-362.

QUAN, C., LI, M., DU, Q., CHEN, Q., WANG, H., CAMPBEll, D., FANG, L., XUE, B., MACKINTOSH, C., GAO, X., OUYANG, K., WANG, H. Y. \& CHEN, S. 2019. SPEG Controls Calcium Reuptake Into the Sarcoplasmic Reticulum Through Regulating SERCA2a by Its Second Kinase-Domain. Circulation Research, 124, 712-726.

QUICK, A. P., WANG, Q., PHILIPPEN, L. E., BARRETO-TORRES, G., CHIANG, D. Y., BEAVERS, D., WANG, G., KHALID, M., REYNOLDS, J. O., CAMPBELL, H. M., 
SHOWELl, J., MCCAUlEY, M. D., SCHOLTEN, A. \& WEHRENS, X. H. T. 2017. SPEG (Striated Muscle Preferentially Expressed Protein Kinase) Is Essential for Cardiac Function by Regulating Junctional Membrane Complex Activity. Circulation Research, 120, 110-119.

RÍOS, E. \& GYÖRKE, S. 2009. Calsequestrin, triadin and more: the molecules that modulate calcium release in cardiac and skeletal muscle. The Journal of Physiology, 587, 3069-3070.

ROMERO, N. B. \& BITOUN, M. 2011. Centronuclear Myopathies. Seminars in Pediatric Neurology, 18, 250-256.

SABHA, N., VOLPATTI, J. R., GONORAZKY, H., REIFLER, A., DAVIDSON, A. E., LI, X., ELTAYEB, N. M., DALl'ARMI, C., DI PAOLO, G., BROOKS, S. V., BUJ-BELLO, A., FELDMAN, E. L. \& DOWLING, J. J. 2016. PIK3C2B inhibition improves function and prolongs survival in myotubular myopathy animal models. Journal of Clinical Investigation, $126,3613-3625$.

STAINIER, D. Y. R. 2001. Zebrafish genetics and vertebrate heart formation. Nature Reviews Genetics, 2, 39-48.

TANG, J., MA, W., CHEN, Y., JIANG, R., ZENG, Q., TAN, J., JIANG, H., LI, Q., ZHANG, V. W., WANG, J., TANG, H. \& LUO, L. 2019. Novel SPEG variant cause centronuclear myopathy in China. Journal of Clinical Laboratory Analysis, 34.

TASFAOUT, H., COWLING, B. S. \& LAPORTE, J. 2018. Centronuclear myopathies under attack: A plethora of therapeutic targets. Journal of Neuromuscular Diseases, 5, 387-406.

THISSE, C. \& THISSE, B. 2007. High-resolution in situ hybridization to whole-mount zebrafish embryos. Nature Protocols, 3, 59-69.

TREVES, S., VUKCEVIC, M., MAJ, M., THURNHEER, R., MOSCA, B. \& ZORZATO, F. 2009. Minor sarcoplasmic reticulum membrane components that modulate excitation-contraction coupling in striated muscles. The Journal of Physiology, 587, 3071-3079.

WANG, H., CASTIGLIONI, C., KAÇAR BAYRAM, A., FATTORI, F., PEKUZ, S., ARANEDA, D., PER, H., ERAZO, R., GÜMÜŞ, H., ZORLUDEMIR, S., BECKER, K., ORTEGA, X., BEVILACQUA, J. A., BERTINI, E. \& CIRAK, S. 2017. Insights from genotype-phenotype correlations by novel SPEG mutations causing centronuclear myopathy. Neuromuscular Disorders, 27, 836-842.

WANG, H., SCHÄNZER, A., KAMPSCHULTE, B., DAIMAGÜLER, H.-S., LOGESWARAN, T., SCHLIERBACH, H., PETZINGER, J., EHRHARDT, H., HAHN, A. \& CIRAK, S. 2018. A 
novel SPEG mutation causes non-compaction cardiomyopathy and neuropathy in a floppy infant with centronuclear myopathy. Acta Neuropathologica Communications, 6, 83.

WILMSHURST, J. M., LILliS, S., ZHOU, H., PILlAY, K., HENDERSON, H., KRESS, W., MÜlleR, C. R., NDONDO, A., ClOKE, V., CUlluP, T., BERTINI, E., BOENNEMANN, C., STRAUB, V., QUINLIVAN, R., DOWLING, J. J., AL- SARRAJ, S., TREVES, S., ABBS, S., MANZUR, A. Y., SEWRY, C. A., MUNTONI, F. \& JUNGBLUTH, H. 2010. RYR1 mutations are a common cause of congenital myopathies with central nuclei. Annals of Neurology, 68, 717-726.

WINTER, D. L., PAULIN, D., MERICSKAY, M. \& LI, Z. 2013. Posttranslational modifications of desmin and their implication in biological processes and pathologies. Histochemistry and Cell Biology, 141, 1-16.

WITHERSPOON, J. W. \& MEILLEUR, K. G. 2016. Review of RyR1 pathway and associated pathomechanisms. Acta Neuropathologica Communications, 4, 121.

WIUM, E., DULHUNTY, A. F. \& BEARD, N. A. 2016. Three residues in the luminal domain of triadin impact on Trisk 95 activation of skeletal muscle ryanodine receptors. Pflügers Archiv - European Journal of Physiology, 468, 1985-1994.

ZANOTEli, E., VERGANI, N., CAMPOS, Y., VAINZOF, M., OLIVEIRA, A. S. \& D'AZZO, A. 2009. Mitochondrial alterations in dynamin 2-related centronuclear myopathy. Arq Neuropsiquiatr, 67, 102-104.

ZHANG, G., XU, M., HUANG, T., LIN, W., CHEN, J., CHEN, W. \& CHANG, X. 2021. Clinical and genetic analysis of a case with centronuclear myopathy caused by SPEG gene mutation: a case report and literature review. BMC Pediatrics, 21, 209.

ZHANG, L., KELlEY, J., SCHMEISSER, G., KOBAYASHI, Y. M. \& JONES, L. R. 1997. Complex Formation between Junctin, Triadin, Calsequestrin, and the Ryanodine Receptor. Journal of Biological Chemistry, 272, 23389-23397.

ZHAO, M., SMITH, L., VOLPATTI, J., FABIAN, L. \& DOWLING, J. J. 2019. Insights into wildtype dynamin 2 and the consequences of DNM2 mutations from transgenic zebrafish. Human Molecular Genetics, 28, 4186-4196. 


\section{Figure \& Legends}

Fig.1

A

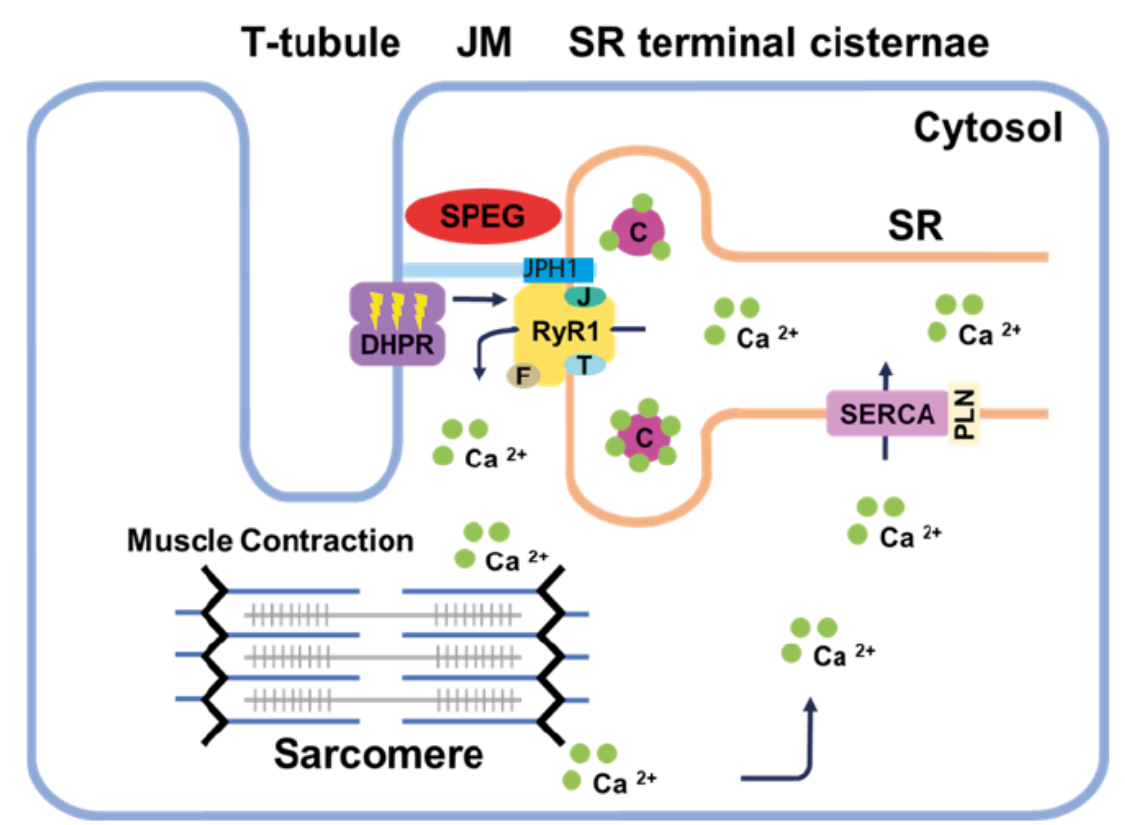

B

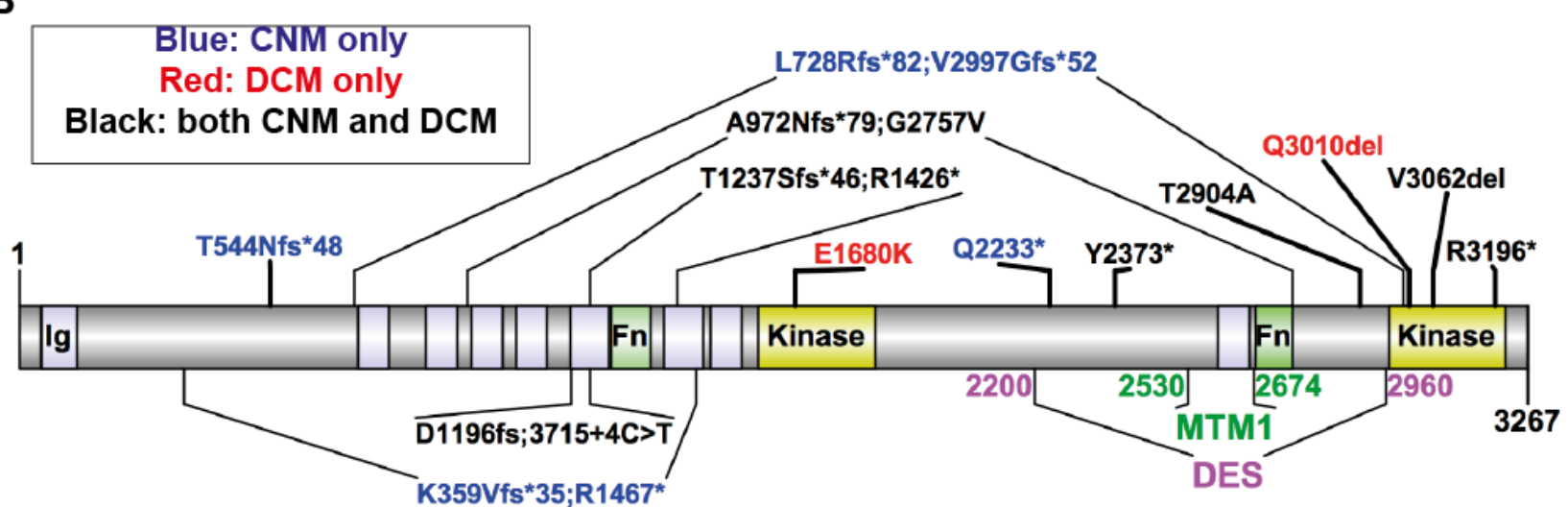

Figure 1. Schematic diagrams of (A) excitation-contraction coupling (ECC) at the triad and (B) SPEG domains and pathogenic variants.

(A) The triads are made of transverse tubules (T-tubules) flanked by terminal sarcoplasmic reticulum (tSR). Junctional membranes (JM) are connected by the interaction of the ryanodine receptor (RyR1) at the tSR, and dihydropyridine receptor (DHPR) at the T-tubules, forming the core components of the ECC machinery. ECC starts when a neuronal action potential arrives via T-tubules and causes a conformational change in DHPR, allowing it to interact with RyR1, causing its activation. As a result, calcium $\left(\mathrm{Ca}^{2+}\right)$ leaves the SR via RyR1 channel opening and moves into the cytosol, promoting sarcomeric contraction. Finally, RyR1 is closed and the calcium transporter SERCA (sarco/endoplasmic reticulum Ca2+-ATPase, regulated by PLN or phospholamban) returns calcium into the SR, where it is largely bound to calsequestrin (C). The terminal SR also contains RyR1 modulators, such as junctophilin-1 (JPH1), FK506binding protein 1A $(\mathrm{F})$, junctin $(\mathrm{J})$; and triadin $(\mathrm{T})$. SPEG (striated muscle enriched protein kinase) is 
localized at the triad, but its role remains elusive.

(B) SPEG contains immunoglobulin domains (Ig, light purple shaded), fibronectin domains (Fn, light green shaded), and two kinase domains (yellow shaded). SPEG directly binds to Myotubularin 1 (MTM1, dark green; SPEG 2530 2674 a.a.) (Agrawal et al., 2014), and Desmin (DES, magenta; SPEG 2200 2960 a.a.) (Luo et al., 2021) at the inter-kinase domain. Pathogenic variants in SPEG span different regions of the gene and are typically nonsense mutations that result in decreased SPEG levels. The variants exist either in compound heterozygosity (e.g. K359Vfs*35; R1467*), or homozygosity (e.g. T544Nfs*48). SPEG mutations can cause a skeletal muscle disorder only (i.e. centronuclear myopathy or CNM, blue fonts), a cardiomyopathy only (e.g. dilated cardiomyopathy, red fonts), or both (black fonts), with no clear genotype-phenotype correlation. Illustrations were made using Illustrator for Biological Sciences (IBS) (Liu et al., 2015). 
Fig.2
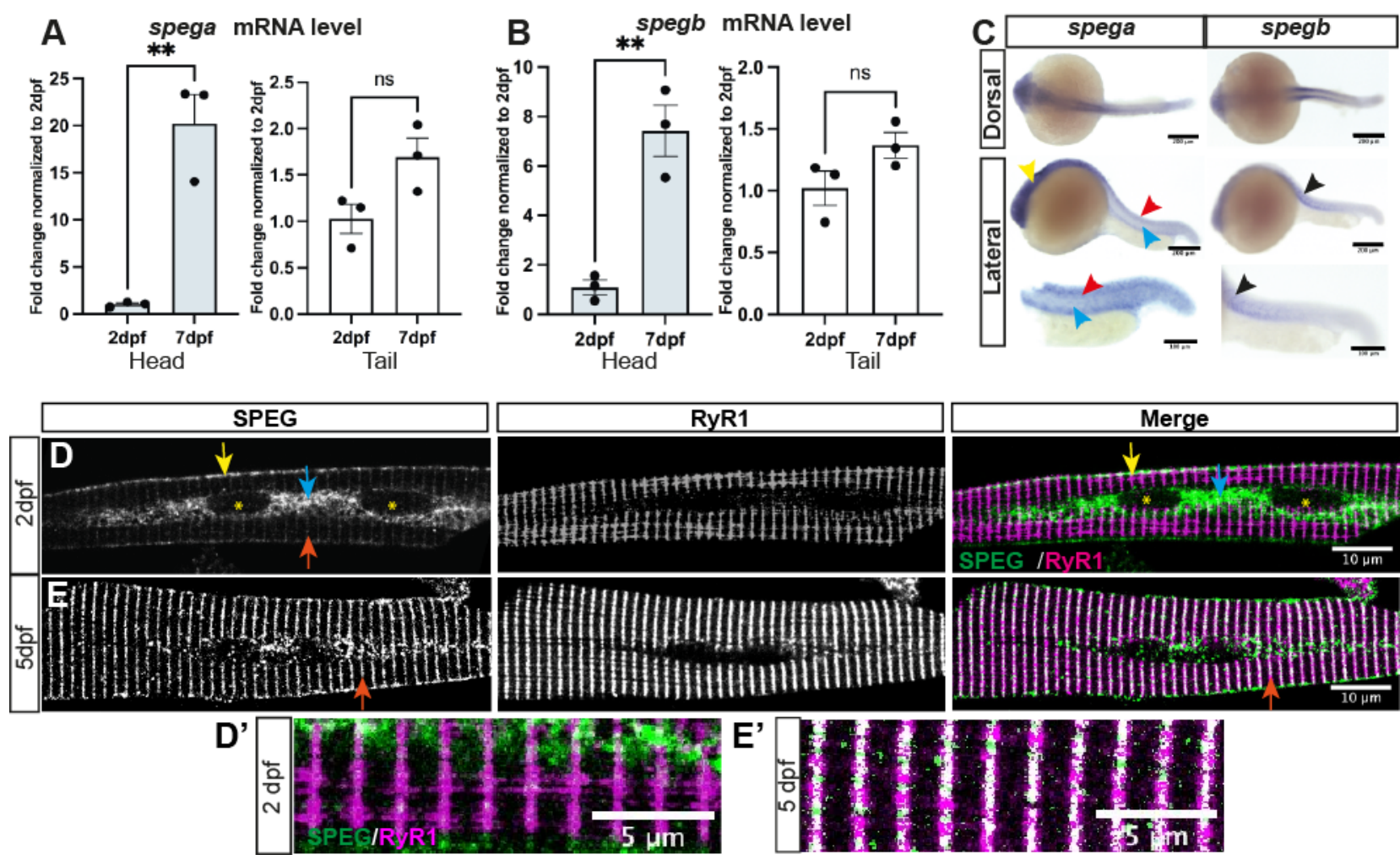

Figure 2. speg expression during zebrafish development.

There are two SPEG genes in zebrafish, spega and spegb. Each encodes a single transcript that is highly conserved with human SPEG. (A-B) RT-qPCR shows similar temporal expression patterns of spega (A) vs spegb (B) from 2 dpf (day-post-fertilization) to $7 \mathrm{dpf}$. Both SPEG mRNA transcripts are significantly upregulated in the heads (gray bars; 20-fold for spega, and 7-fold for spegb), but stay at relatively similar levels in the skeletal-muscle-predominant tails (white bars). Each data point represents the average of technical triplicates, and three independent experiments are included. Columns and error bars represent Mean \pm SEM. Two-tailed Student's $t$-test was performed: **, $P<0.01$; ns, not significant. (C) Wholemount in situ hybridization using DIGconjugated RNA probes in 1 dpf embryos show distinct spatial expression patterns of spega vs spegb. spega is predominantly expressed in the developing brain (yellow arrowhead) and along the neural tube (red arrowheads), but absent from the notochord (cyan arrowheads). spegb staining, however, is predominantly detected at the chevron-shaped developing somites (black arrowheads). In situ images - scale bars: $200 \mu \mathrm{m}$ (upper, middle) or $100 \mu \mathrm{m}$ (bottom). (D-E) Average Zprojections of confocal images showing $2 \mathrm{dpf}(\mathbf{D})$ or $5 \mathrm{dpf}(\mathbf{E})$ isolated wildtype skeletal myofibres double-stained with anti-RyR1 (34C, DSHB) and anti-SPEG (PA553875, Invitrogen). (D and D') At $2 \mathrm{dpf}$, SPEG is predominantly localized at the sarcolemma (yellow arrows) and perinuclear regions (cyan arrows; nucleus: yellow asterisks) with weak expression in transverse striations 
(orange arrows), whereas RyR1 is localized in transverse striations labeling the terminal sarcoplasmic reticulum (SR). Little co-localization (white in Merge) of SPEG (green) and RyR1 (magenta) can be observed at this stage. (E and E') At 5 dpf, SPEG expression becomes restricted in the transverse striations (orange arrows) that overlap with RyR1. IF images - scale bars: $10 \mu \mathrm{m}$ for D and E, $5 \mu \mathrm{m}$ for D' and E'. 
Fig.3

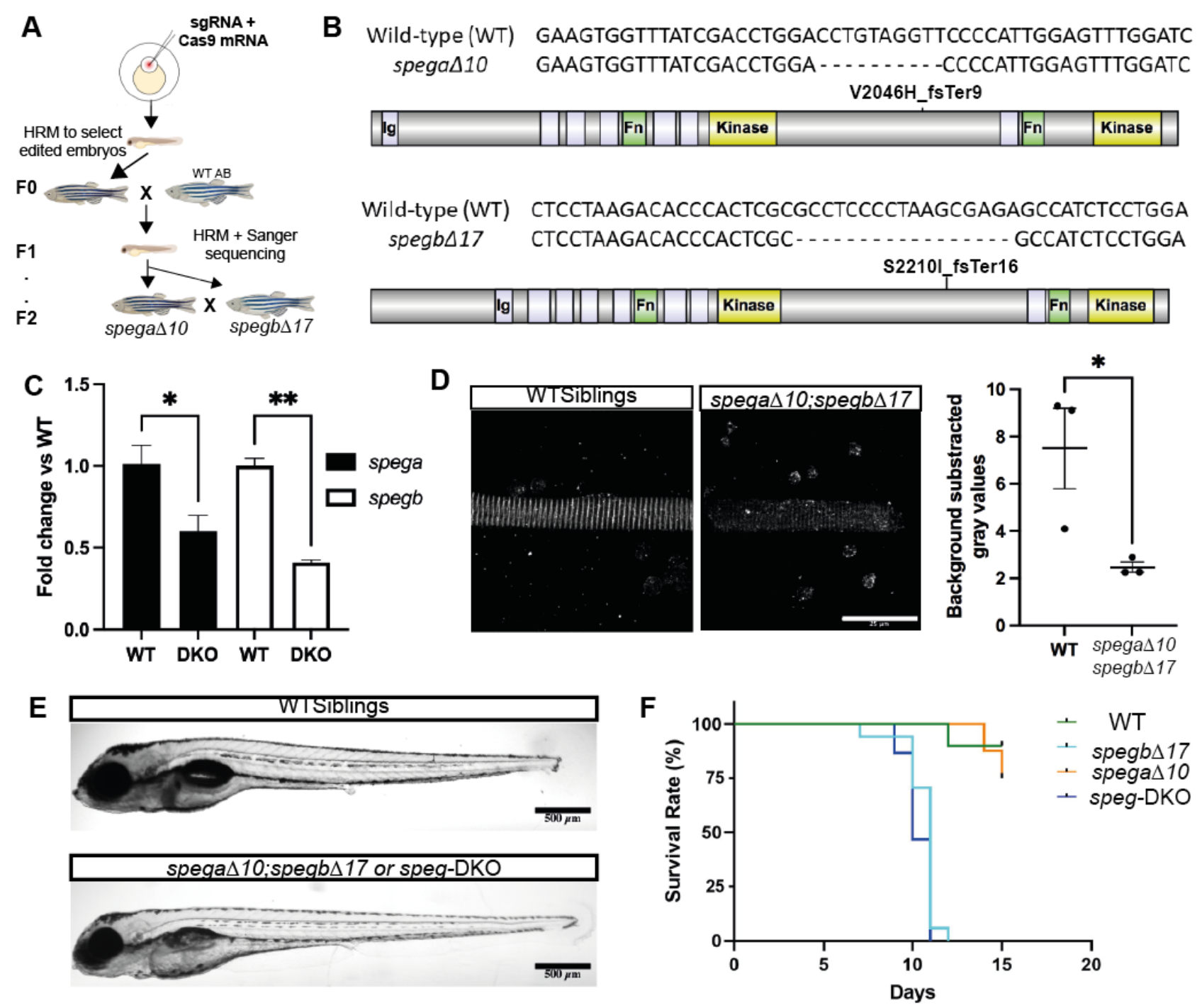

Figure 3. Generation of speg knockout zebrafish

(A) Schematic diagram showing the workflow of generating speg single and double CRISPR-Cas9 mutants. gRNAs (against spega or spegb) showing high editing efficiency (as determined by HRM) were co-injected with Cas9 mRNA into 1-cell stage embryos (AB strain), and the resulting larvae were raised to adulthood. These F0 zebrafish were then outcrossed to wildtype AB, and resulting embryos screened for germline mutation by HRM and Sanger sequencing. Larvae that showed nucleotide changes leading to premature stop codons were raised to adulthood (F1), i.e. spega single $\mathrm{KO}$ (spega $\Delta 10)$, or spegb single $\mathrm{KO}$ (spegb $\Delta 17)$. To dilute off-target effects, F1 adults were outcrossed to AB wildtypes to generate $\mathrm{F} 2$ embryos

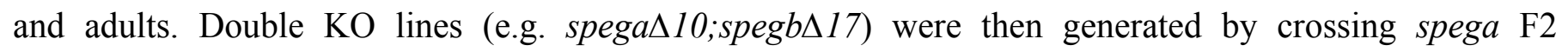
heterozygous (+/-) adults to spegb F2 heterozygous (+/-) adults,. (B) Genotypes and predicted protein products (if any) of the single mutant lines. spega-V2046H_fsTer9: V2046 $>\mathrm{H}$, frame shift and terminates in 9 amino acids downstream. spegb-S2210I_fsTer16: S2210>I, frame shift and terminates in 16 amino acids downstream. (C) RT-qPCR analysis shows significant reductions (around 50\%) in both spega (black 


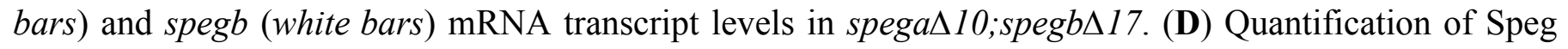
protein levels as measured by immunofluorescence (IF, anti-SPEG) intensity in 5 dpf myofibres isolated from WT siblings vs spega $\Delta$ 10; spegb $\Delta 17$. Each dot represents the average of gray values (technical triplicates) measured by the square tool in Fiji ImageJ. Three independent experiments were performed, and error bars are shown as Mean \pm SEM. Two-tailed Student's $t$-test: ${ }^{*}, P<0.05$. ${ }^{* *}, P<0.01$. Scale bar: 25 $\mu \mathrm{m}$. (E) At 6 dpf, morphology was similar between WT siblings and spega $\Delta$ 10;spegb 17 (or speg-DKO), though deflated swim bladder was noted in speg-DKOs. Scale bars: $500 \mu m$. (F) Representative KaplanMeier curve showing reduced survival in spegbs17 (spega +/+; spegb-KO, light blue) and speg-DKO (spega-KO; spegb-KO, dark blue), but not in spegas10 (spega-KO; spegb +/+, orange) or WT siblings (spega $+/+$; spegb +/+, green). spegb-KO and speg-DKO larvae have a median survival of 11 and $10 \mathrm{dpf}$, respectively; and a maximum survival of 12 and $11 \mathrm{dpf}$, respectively. $\mathrm{N}=10 \mathrm{WT}, \mathrm{n}=17$ spegb-KO, n=16 spega-KO, and n=15 speg-DKO. Mantel-Cox test: ****, $P<0.0001$. 
Fig.4

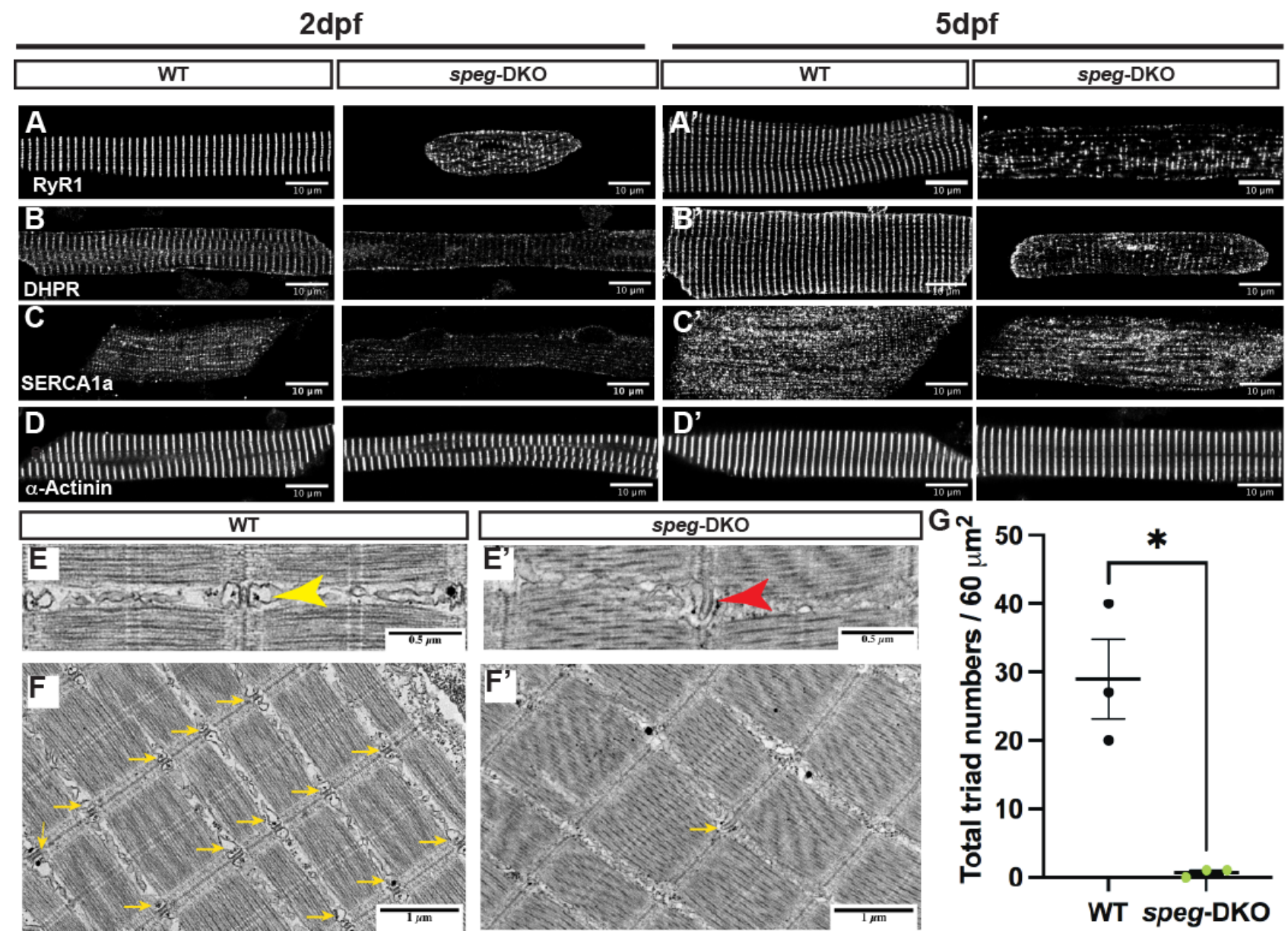

Figure 4. speg deficiency in zebrafish disrupts triad protein organization and triad ultrastructure, leading to reduced triad numbers.

Immunofluorescence staining was performed on $2 \mathrm{dpf}(\mathbf{A}-\mathbf{D})$ and $5 \mathrm{dpf}\left(\mathbf{A}^{\prime}-\mathbf{D}^{\prime}\right)$ isolated myofibres. Average projections of confocal Z-stacks show disrupted transverse pattern of RyR1 (A and A'), DHPR (B and B'), and SERCA1a (D ad D') in speg-DKO starting from 2 dpf, while $\alpha$-Actinin (D and D') is not affected. IF images - scale bars: $50 \mu \mathrm{m}$. (E-F) Electron micrographs of $7 \mathrm{dpf}$ WT and speg-DKO muscles. (E) In WT zebrafish skeletal muscle, normal triads are physically above the sarcomeric Z-disks, and composed of centrally-located T-tubules flanked by terminal sarcoplasmic reticulum (yellow arrows). (E') Triads in speg-DKO appear structurally disrupted, losing the obvious tSR/T-tubule/tSR pattern (red arrows). More importantly, (F) the majority of sarcomeric Z-disks in speg-DKO do not have adjacent triads (yellow arrows). EM images - scale bars: (E) $0.5 \mu \mathrm{m}$; (F) - $1 \mu \mathrm{m}$. (G) The total number of triads per $60 \mu \mathrm{m}^{2}$ (under electron microscopy) was significantly reduced in speg-DKO. Each dot represents the average of technical triplicates, and three biological replicates are included. Error bars are shown as Mean \pm SEM. Two-tailed Student's t-test: $*, P<0.05$. 
Fig.5

A WT

spega-KO (aKO)

spegb-KO (bKO)

speg-DKO (DKO)

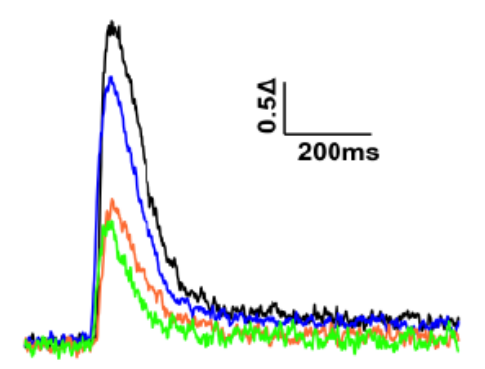

D

$10 \mathrm{~Hz}$ STEADY STATE

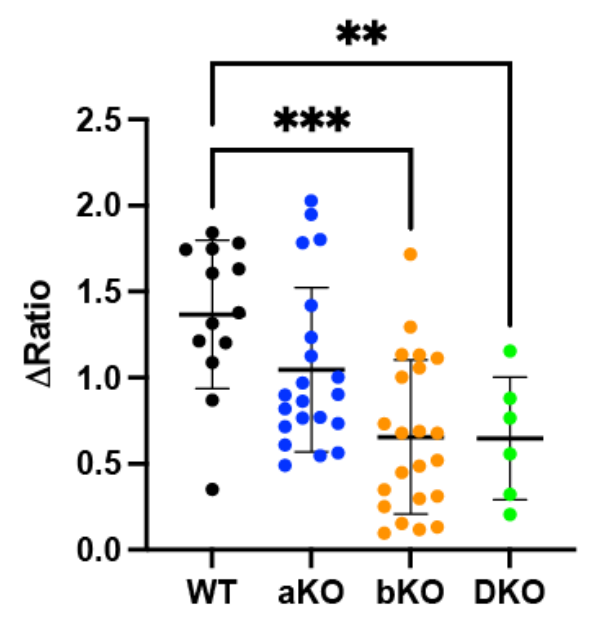

B

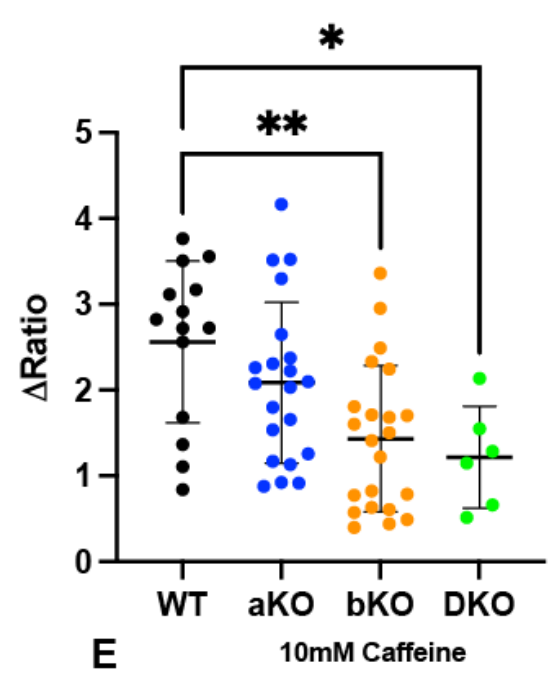

C

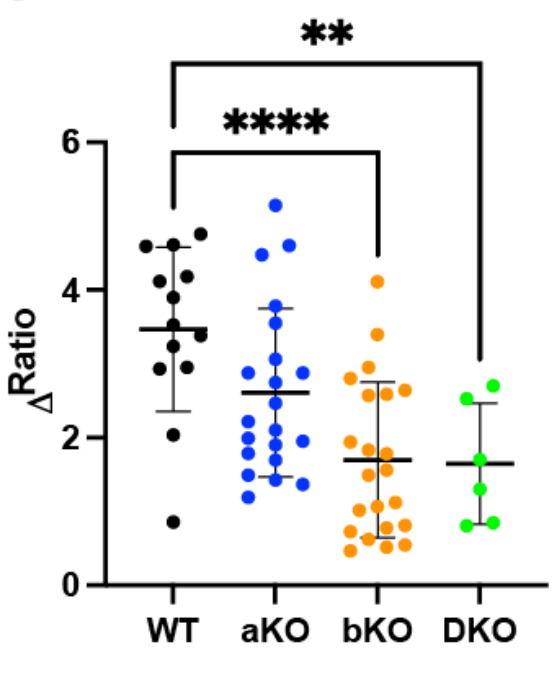

F

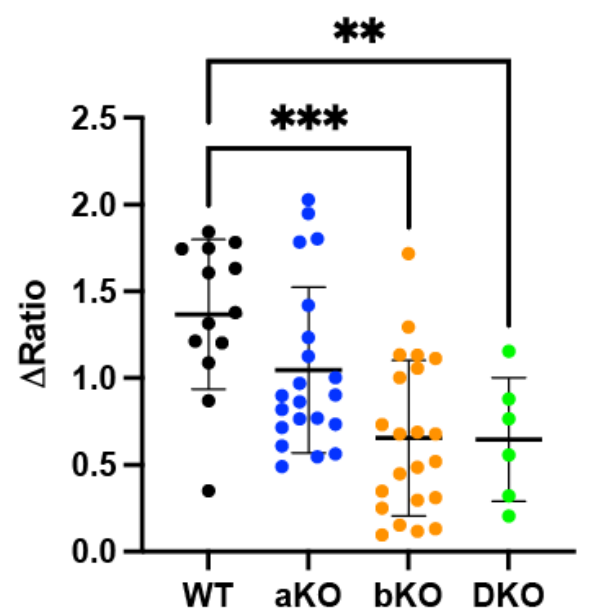

G

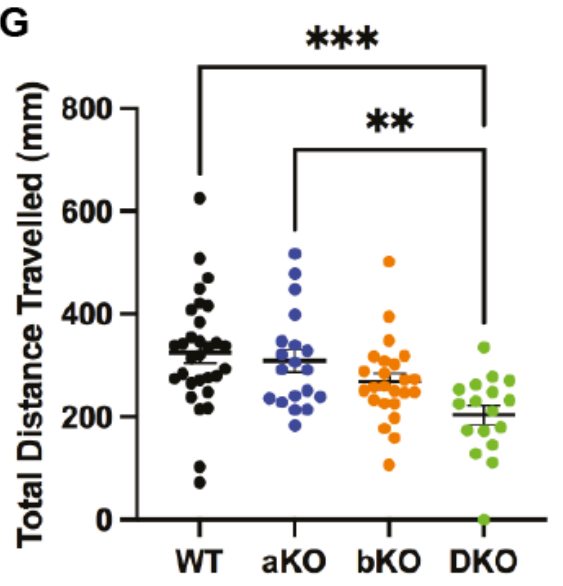

Figure 5. speg deficiency in zebrafish disrupts excitation-contraction coupling (ECC) in isolated myofibres and impairs overall muscle performance

(A-E) Cytosolic $\mathrm{Ca}^{2+}$ transients in $7 \mathrm{dpf}$ isolated myofibres were measured using a $\mathrm{Ca}^{2+}$ sensitive dye fluo4-AM: (A) A representative diagram of $\mathrm{Ca}^{2+}$ transient traces. (B) Five-twitch $1 \mathrm{~Hz}$ 
stimulations were followed by (C-D) one $10 \mathrm{~Hz}$ stimulation, and (E) $30 \mathrm{sec}$ of $10 \mathrm{mM}$ caffeine. Overall, spegb-KO (bKO) and speg-DKO (DKO) showed significantly reduced ECC compared to WT and spega-KO (aKO). (F) A representative image of swim trace tracking using ZebraBox in a 96-well plate setting, by which total distance travelled ( $\mathrm{mm}$ ) was quantified for each $3 \mathrm{dpf}$ zebrafish per well. (G) Both spegb-KO and speg-DKO swam significantly less distance than WT and spegaKO. All statistical analyses include three independent experiments: for fluo4-AM experiments (BE), each dot represents one myofibre, at least $n=5$ myofibres per group per experiment; for swimming assay $(\mathrm{G})$, each dot represents a 3 dpf zebrafish, at least $\mathrm{n}=5$ zebrafish per group per experiment. Error bars are shown as Mean \pm SEM. One-way ANOVA: $*, P<0.05 ; * *, P<0.01$; ***, $P<0.001 ; * * * *, P<0.0001$. Note - WT (black line or dots); aKO: spega-KO (blue line or dots); bKO: spegb-KO (orange line or dots); DKO - spega/b double KO (green line or dots). 
Fig. 6
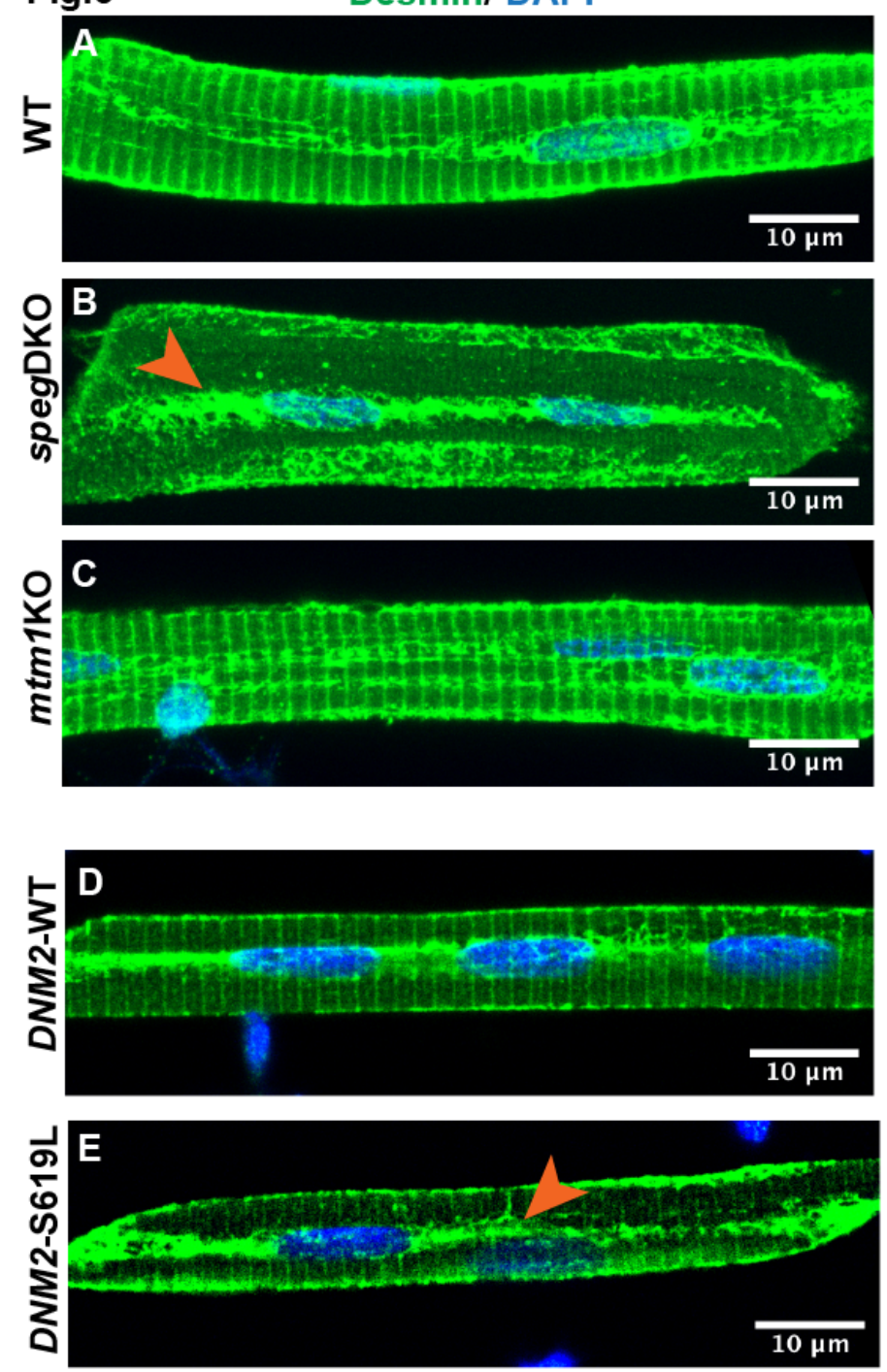

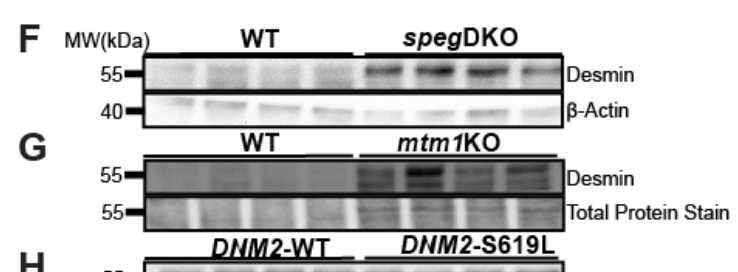

H

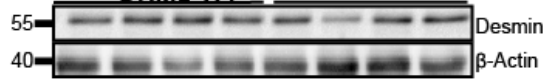

$\mathbf{F}^{\prime}$

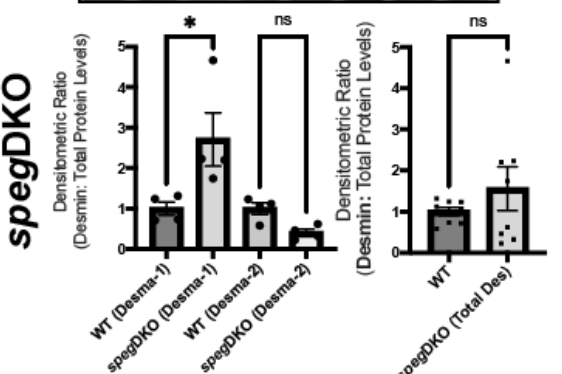

G'
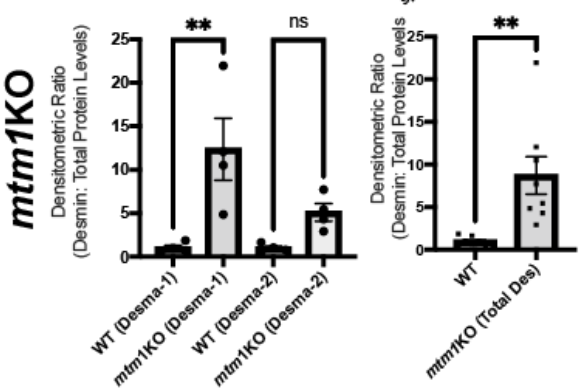

$\mathrm{H}^{\prime}$

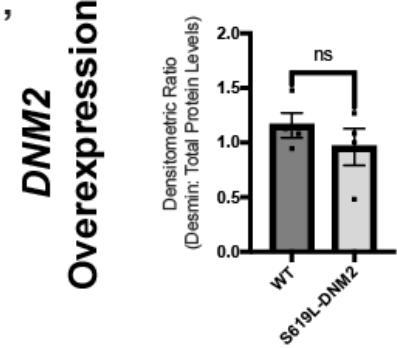

Figure 6. Desmin subcellular localization and protein levels in zebrafish models of CNM.

(A-D) Myofibres were isolated at $5 \mathrm{dpf}$ (speg-DKO), $7 \mathrm{dpf}(\mathrm{mtm} 1-\mathrm{KO})$ and $3 \mathrm{dpf}(\mathrm{DNM} 2$ overexpression), and stained with anti-Desmin (green; D8281, Sigma) and DAPI (blue, nucleus). (A) At 5 dpf, Desmin is normally localized to the sarcolemma, perinucleus, and the sarcomeric Zdisks (as transverse striations). (B) In speg-DKO (5 dpf), Desmin is predominantly localized to the perinucleus (orange arrowhead). (C) In $m t m l-K O ~(7 \mathrm{dpf}$ ), Desmin localization appears similar to wildtype (WT) siblings. (D) WT-DNM2-EGFP overexpressing myofibres show similar Desmin staining pattern to non-transgenic WTs, while (E) S619L-DNM2-EGFP overexpressing myofibres show loss of Desmin in transverse striations, with Desmin localization predominantly at the perinucleus (orange arrowhead). IF images - scale bars: $10 \mu \mathrm{m}$. (F-H, F'-H') Western blot analysis using whole zebrafish lysates shows Desmin upregulation in (F and $\left.\mathbf{F}^{\prime}\right) 5$ dpf speg-DKO (by 2-3 fold) and in (G and $\left.\mathbf{G}^{\prime}\right) 7 \mathrm{dpf} m t m 1-\mathrm{KO}$ (by 5-10 fold) when compared to WT siblings, but not in (H and H') 3 dpf DNM2-S619L zebrafish when compared to DNM2-WT controls. Each lane 
(F-H) or each $\operatorname{dot}$ (F'-H') represents $n=25$ zebrafish (40 $\mu \mathrm{g}$ of total proteins), four lanes represent four independent experiments. Densitometry was measured using Fiji ImageJ. Desmin protein levels were normalized to $\beta$-actin loading controls in speg-DKO and DNM2, or to REVERT total protein stains in $m t m 1-\mathrm{KO}$ (as $\beta$-actin level is changed by the lack of MTM1). Error bars are shown as Mean \pm SEM. Two-tailed Student's $t$-test: *, $P<0.05$; **, $P<0.01$; ns, not significant. 

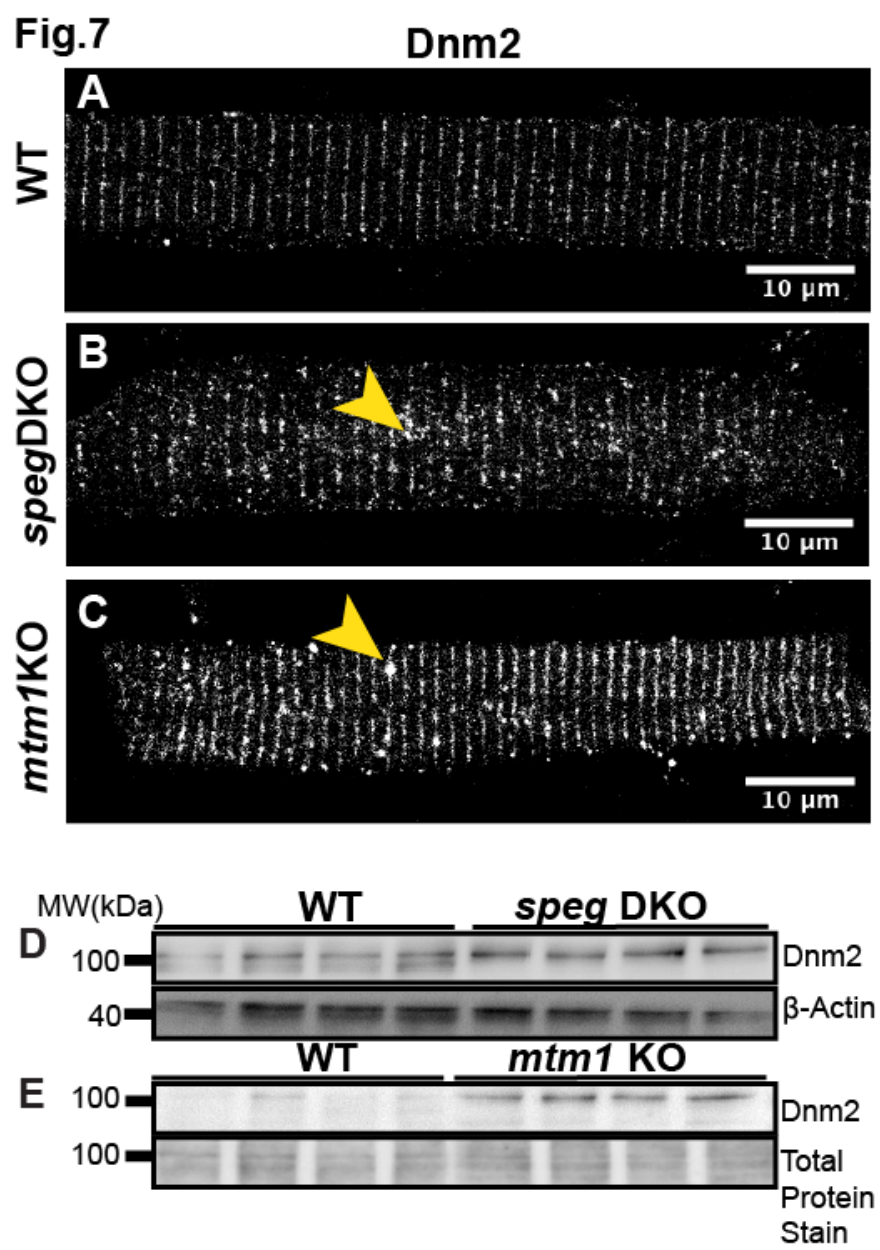
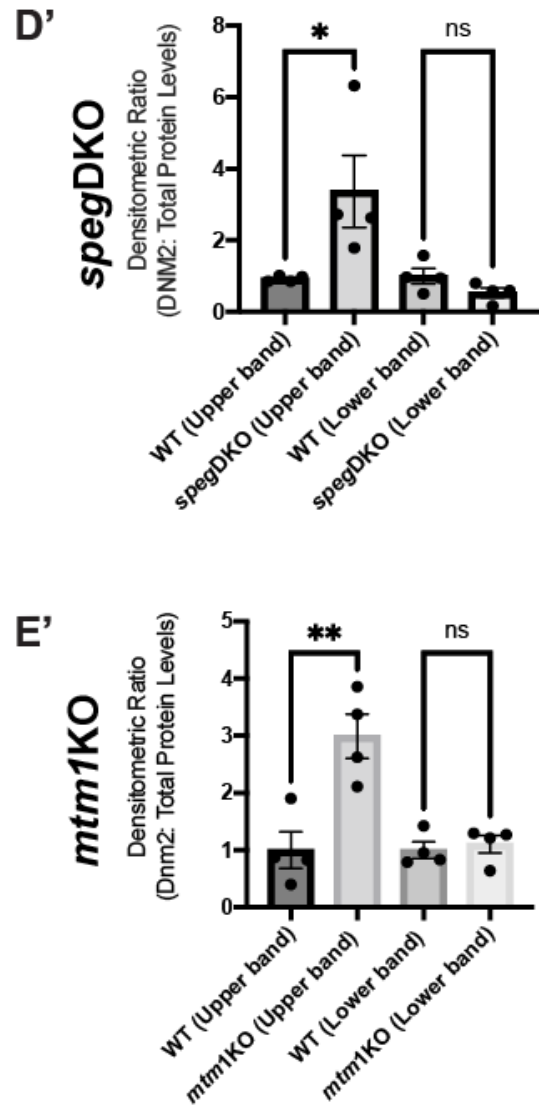

Figure 7. Dnm2 protein is upregulated in both speg-DKO and mtm1-KO zebrafish

(A-C) Myofibres were isolated at $5 \mathrm{dpf}(\mathrm{speg}-\mathrm{DKO})$ and $7 \mathrm{dpf}(\mathrm{mtm} 1-\mathrm{KO})$, and stained with antiDnm2 (GTX127330, GeneTex). (A) In wildtype myofibres (5 dpf), Dnm2 is localized to the triads (transverse striations). Similar striated patterns can be observed for Dnm2 in (B) speg-DKO and (C) mtm1-KO, with occasional Dnm2 aggregations observed along the striations (yellow arrowheads). IF images - scale bars: $10 \mu \mathrm{m}$. (D-E) Western blot analysis shows increased Dnm2 protein levels in (D and D') $5 \mathrm{dpf}$ speg-DKO and (E and E') $7 \mathrm{dpf} m t m 1-\mathrm{KO}$ when compared to WT. Each lane (D-E) or each dot (D'-E') represents $n=25$ zebrafish (40 $\mu \mathrm{g}$ of total protein). Densitometry was accomplished using Fiji ImageJ. Dnm2 protein level was normalized to $\beta$-actin loading controls in speg-DKO, or to REVERT total protein stains in $m t m 1-\mathrm{KO}$ (as $\beta$-actin level is changed by the lack of MTM1). Students $t$-test: *, $P<0.05$; **, $P<0.01$; ns, not significant. 
Fig. S1
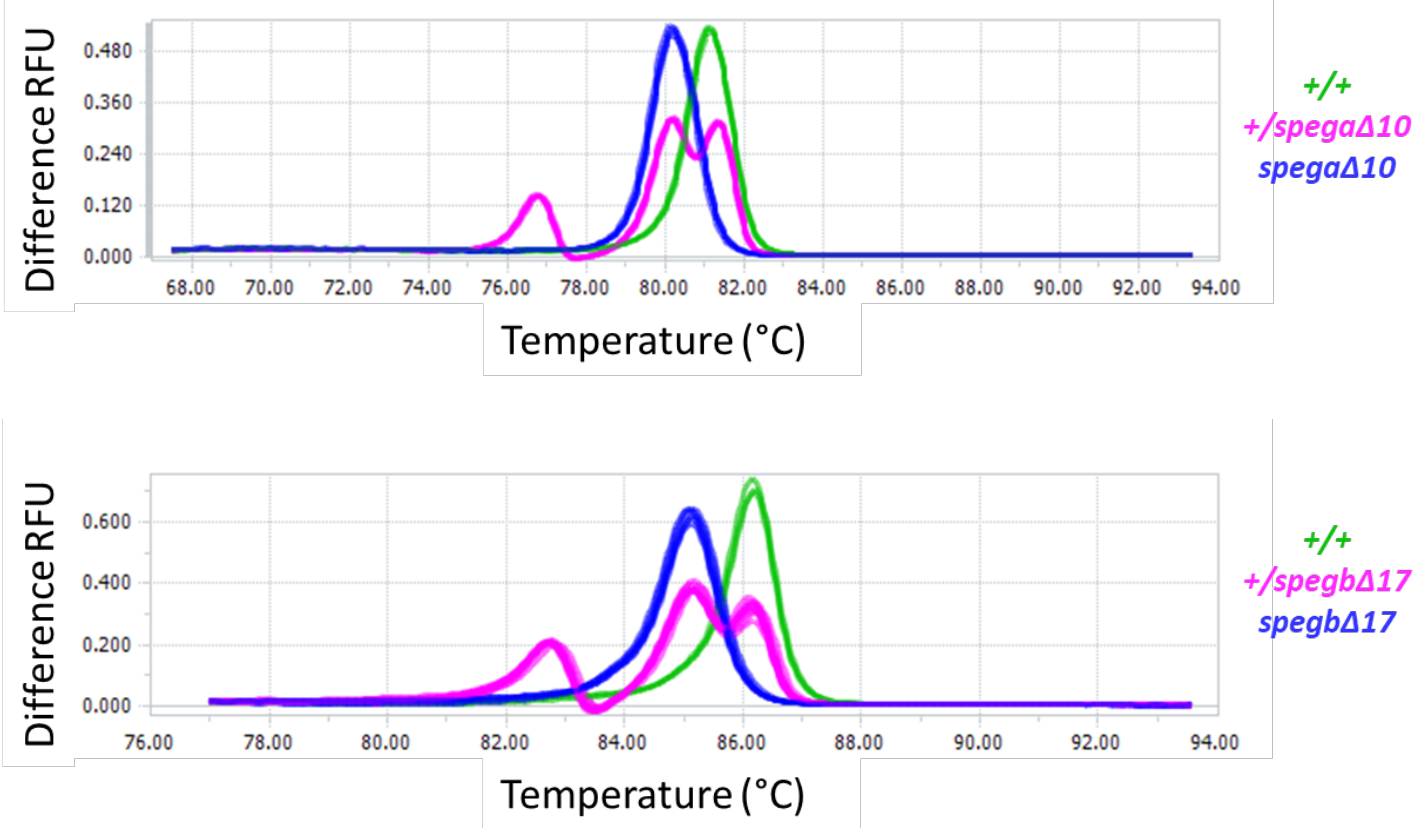

\section{Supplementary Figure 1. spega $\Delta 10$;spegb $\Delta 17$ mutant zebrafish genotyping.}

High Resolution Melting (HRM) analysis was used to genotype spega (top) and/or spegb (bottom) CRISPR lines. Wildtype (green), Heterozygous (magenta), and Homozygous mutants (blue). RFU: relative fluorescence units. 
Fig. 52
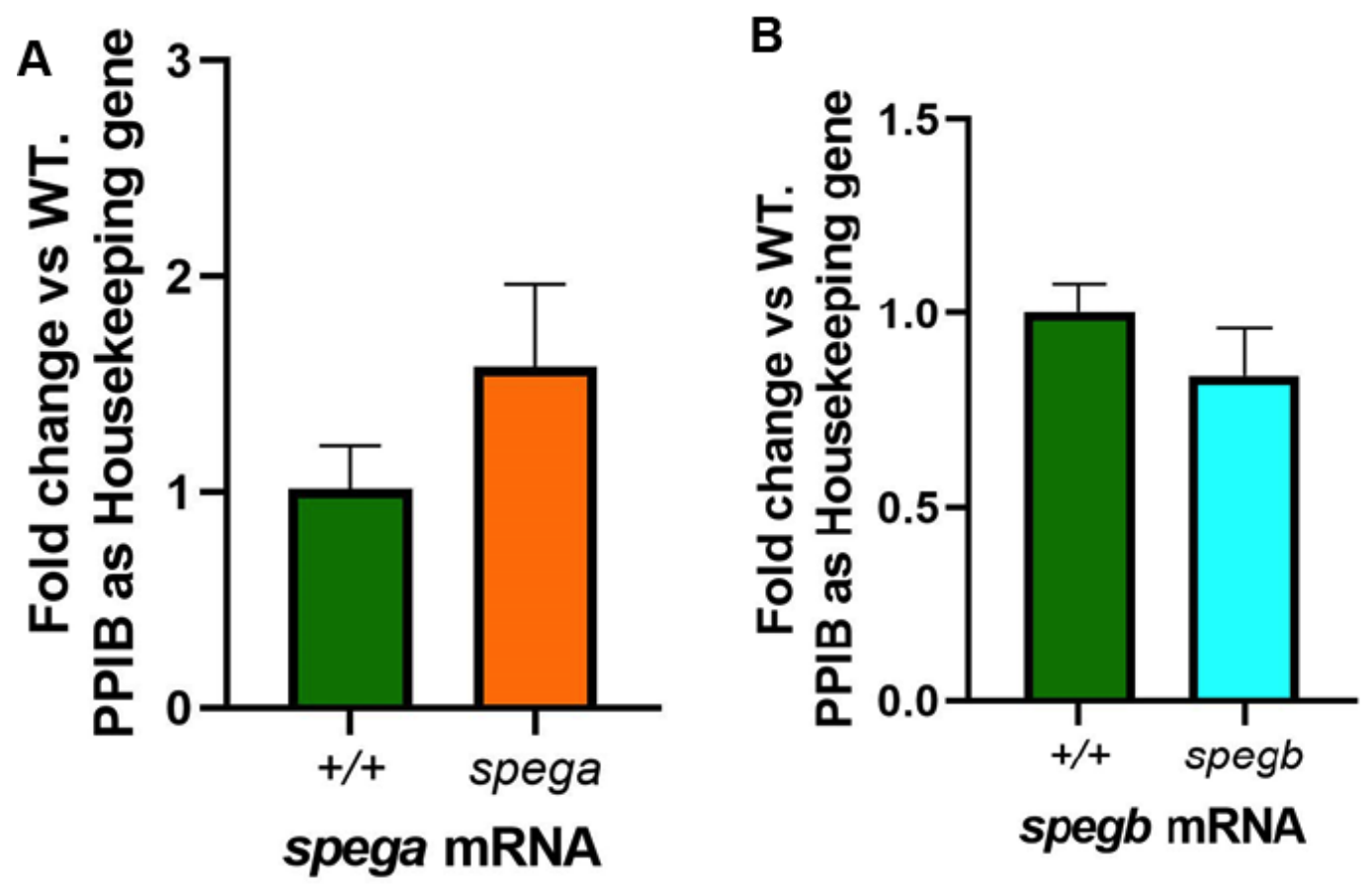

Supplementary Figure 2. RT-qPCR analysis on single mutants.

No significant changes were observed at $7 \mathrm{dpf}$ for the levels of spega mRNA in spegas10-KO (A), or spegb mRNA in spegb $\Delta 17-\mathrm{KO}$ (B). Levels of expression were first normalized to the housekeeping gene ppib, and then to WT. Results represent three independent experiments (technical triplicates per experiment). $\mathrm{N}=10-15$ embryos per genotype per independent experiment. Columns and error bars represent Mean \pm SEM. Two-tailed Student's $t$-test was performed: ns, not significant. 


\section{Fig. S3}

A
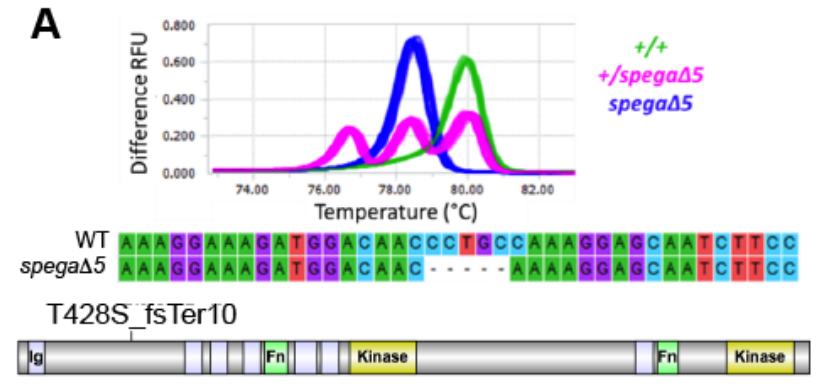

B
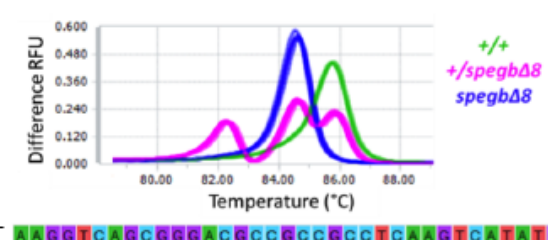

AGTCATATGGAGCC
AGTCATATGGAGCC

P819_fsTer32

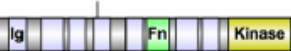

$$
\begin{aligned}
& \text { C } \mathrm{n}=5+\mathrm{WT} \\
& \mathrm{n}=18+\text { spegb }+/- \\
& \mathrm{n}=5+\text { spegb single } \mathrm{KO} \\
& \mathrm{n}=15+\text { spega }+/- \\
& \mathrm{n}=34 \rightarrow \text { spega/b double hets } \\
& \mathrm{n}=13 \text { - spega +/-, spegb KO } \\
& \mathrm{n}=12+\text { spega single } \mathrm{KO} \\
& \mathrm{n}=19+\text { spega KO, spegb +/- } \\
& \mathrm{n}=11+\text { spega/b double } \mathrm{KO}
\end{aligned}
$$

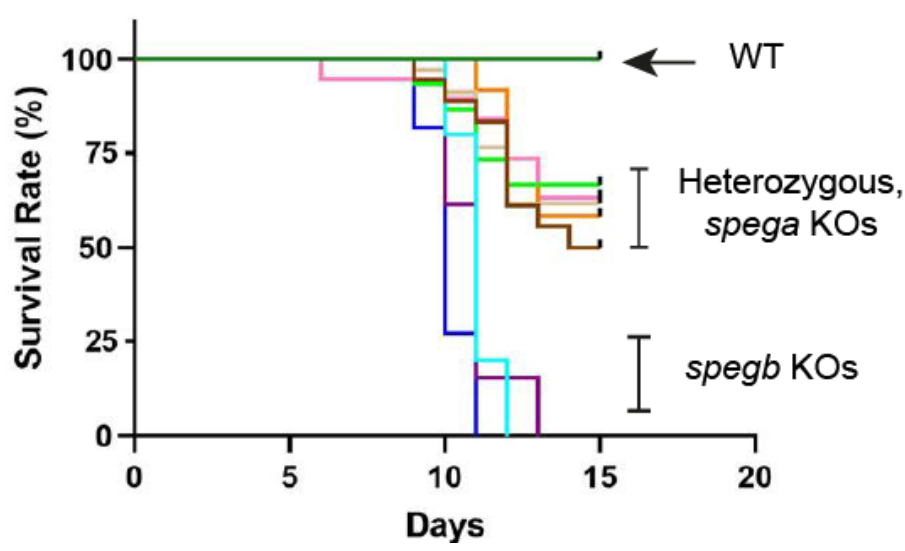

\section{Supplementary Figure 3. Reduced survival in $\operatorname{spega} \Delta 5 ; \operatorname{spegb} \Delta 8$.}

Additional mutant lines were generated to validate the speg-DKO (spega $\Delta 10 ; \operatorname{spegb\Delta 17)}$ survival phenotype. (A and B) HRM and Sanger sequencing confirmed the genotypes of (A) spega $\Delta$, which carries a 5-bp deletion in exon 5 of spega, and (B) spegb $\Delta 8$, which carries an 8-bp deletion in exon 8 of spegb. Both are predicted to cause frame shift (fs) and premature stop codons. (C) Survival analysis across all spega $\Delta 5$ and/or spegb $\Delta 8$ lines: survival was reduced in spegb KOs, spegb KO/spega +/-, and spega/b double knockouts, with a median survival of 11, 11 and 10 dpf, respectively, and a maximum survival of 12,13 and $11 \mathrm{dpf}$, respectively. This represents a significant decrease in survival as zebrafish can live up to $1.5-2$ years (**** $\mathrm{P}<0.0001)$, Mantel-Cox test. In contrast, WT and spega KOs have similar lifespans. 
Fig. 54

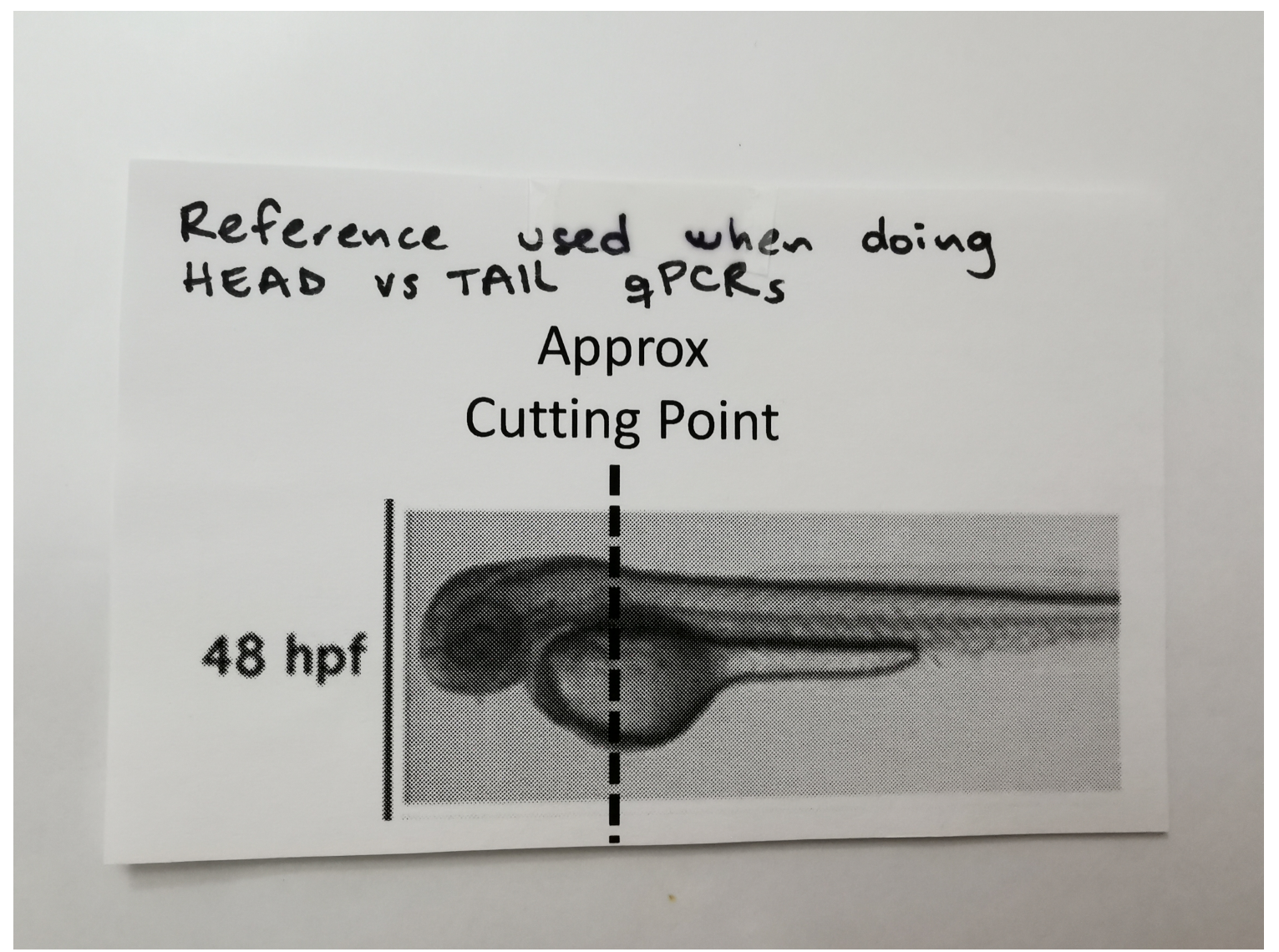

\section{Supplementary Figure 4.}

An illustration showing the approximate cutting point (dotted line) to separate head vs tail for RTqPCR analyses. 